\title{
Diseño e impacto de las prestaciones por hijos a cargo en los países de la OCDE
}

\section{Joseba Zalakain}

SIIS Servicio de Información e Investigación Social

jzalakain@siis.net

Artikulu honetan, SIIS Informazio eta Ikerketa Sozialeko Zerbitzuak Eusko Jaurlaritzako Justizia, Berdintasun eta Gizarte Politiketako Saileko Familia Politikako Zuzendaritzarentzat egindako azterlan batzuen emaitzak jasotzen dira. Lehendabizi, artikuluak ELGAko hogeita hiru herrialdetan semealabak ardurapean dituzten biztanleek jasotako prestazioen ezaugarri nagusiak aztertzen ditu, eta ondoko gaien inguruan argitaratu izan den literatura berrikusi: haur-pobreziaren murrizketa, familien bizi-baldintzen eta osasunaren -eta ongizatearenhobetzea, onuradun diren familien ugalkortasuna eta enplegu-lorpenaren maila, eta, berariaz, ama direnek duten enplegu-lorpenaren maila.

\section{GAKO-HITZAK:}

Familia-politika, prestazio ekonomikoak, zerbitzuebaluazioa, nazioarteko ikuspegia.
Este artículo recoge los resultados de estudios realizados por el SIIS Servicio de Información e Investigación Social para la Dirección de Política Familiar del Departamento de Justicia, Igualdad y Políticas Sociales del Gobierno Vasco. El artículo analiza en primer lugar las principales características de las prestaciones por hijo/a a cargo de veintitrés países de la OCDE y, posteriormente, revisa la literatura publicada sobre su impacto en cuanto a la reducción de la pobreza infantil, la mejora de las condiciones de vida y de salud - y del bienestar- de las familias, la fecundidad y el acceso al empleo de las familias beneficiarias, con especial atención al acceso al empleo de las madres.

\section{Palabras Clave:}

Política familiar, prestaciones económicas, evaluación de servicios, panorama internacional. 


\section{Introducción}

La práctica totalidad de los países de la Organización para la Cooperación y el Desarrollo Económico (OCDE) cuentan con asignaciones familiares por hijo/a a cargo orientadas a compensar los gastos generales que supone la crianza. Junto con el resto de los subsidios y prestaciones familiares - las prestaciones por maternidad y paternidad abonadas por la Seguridad Social para el mantenimiento de rentas durante los primeros meses de vida de los hijos/as o las prestaciones orientadas a compensar los gastos derivados del cuidado infanti ${ }^{1}-$, estas ayudas tienen un impacto relevante desde muy diversos puntos de vista y suponen un importante esfuerzo económico: en el conjunto de la Unión Europea, el gasto destinado a estas ayudas supera los 163.000 millones de euros, lo que representa casi el $1 \%$ del PIB de la Unión y en torno al 3,8\% del gasto en protección social.

La literatura relativa al impacto de estas prestaciones pone de manifiesto que contribuyen al sostenimiento del pacto intergeneracional en el que se basa el Estado del Bienestar, contribuyen a la redistribución vertical y horizontal de la renta, reducen la pobreza infantil, mejoran la situación de los niños/as y de sus familias -incluso a medio y largo plazo- desde el punto de vista educativo y de salud, y tienen un efecto positivo (aunque reducido) en el incremento de la fecundidad. Estas prestaciones son, sin duda, parte fundamental del enfoque de inversión social auspiciado por las instituciones europeas y forman parte del pilar europeo de derechos sociales, según el cual los niños tienen derecho a la protección contra la pobreza y los niños procedentes de entornos desfavorecidos tienen derecho a medidas específicas destinadas a promover la igualdad de oportunidades.

La literatura publicada en relación con el diseño de estas prestaciones permite también afirmar que existe una relación positiva entre el carácter universal de estas prestaciones y su capacidad para la reducción de la pobreza, y que las prestaciones universales presentan, frente a las selectivas 0 focalizadas, más ventajas que inconvenientes. La evidencia disponible apunta en cualquier caso a la necesidad de avanzar hacia un universalismo focalizado (targeting within universalism), en la medida en que las estrategias que han tenido más éxito para abordar la pobreza infantil han demostrado ser las sustentadas en políticas destinadas a mejorar el bienestar de todos los niños y niñas, teniendo especialmente en cuenta, al mismo tiempo, a los niños y a las niñas que se encuentran en situaciones particularmente vulnerables (Comisión Europea, 2013).

${ }^{1}$ En esta categoría se incluyen las prestaciones orientadas a compensar la disminución de ingresos derivada de la reducción o la suspensión de la actividad laboral de alguno de los progenitores mediante excedencias o reducciones de jornada, así como las orientadas a cofinanciar la contratación de servicios de cuidado infantil.
El impulso de estas prestaciones está en la base de los programas de reactivación económicas impulsados por diversos países para hacer frente a las consecuencias de la covid-19: Italia acaba de aprobar una prestación universal de hasta 250 euros por hijo/a a cargo, que reduce la fragmentación del modelo actual y que, como en el caso alemán, se basa en la idea de integrar prestaciones sociales y deducciones fiscales, de forma que las familias podrán percibir la ayuda bien como prestación o bien como deducción. En los Estados Unidos, la Administración Biden ha modificado sustancialmente el Child Care Credit anteriormente existente, ampliando su cuantía y mejorando su alcance. Al menos durante 2021, la deducción será de un máximo de 3.600 dólares anuales, podrá cobrarse íntegramente como prestación neta y no estará limitada a los progenitores con empleo.

Este artículo recoge los resultados de estudios realizados por el SIIS Servicio de Información e Investigación Social para la Dirección de Política Familiar del Departamento de Justicia, Igualdad y Políticas Sociales del Gobierno Vasco², así como el impacto de las prestaciones para la conciliación existentes en la Comunidad Autónoma del País Vasco (CAPV). El artículo analiza en primer lugar las principales características de las prestaciones por hijo/a a cargo de veintitrés países de la OCDE y, posteriormente, revisa la literatura publicada sobre su impacto en cuanto a la reducción de la pobreza infantil, la mejora de las condiciones de vida y de salud -y del bienestar- de las familias, la fecundidad y el acceso al empleo de las familias beneficiarias, con especial atención al acceso al empleo de las madres.

Desde el punto de vista metodológico, el estudio se basa en los siguientes aspectos:

- Se han tenido en cuenta las prestaciones por hijo/a a cargo que ofrecen las distintas Administraciones a las familias con hijos/as para contribuir a su crianza. No se tienen en cuenta, por tanto, ni las prestaciones que en el ámbito de la familia dan respuesta a la pérdida de ingresos por nacimiento y/o para el cuidado de hijos/as (bajas o permisos de paternidad, ayudas a la conciliación, etc.), ni las prestaciones que se dirigen al conjunto de la población, aunque incluyan la presencia de hijos/as en el hogar (como subsidios por desempleo, prestaciones de garantía de ingresos, etc.). Tampoco se contemplan otras ayudas, como becas o similares.

- Las prestaciones analizadas se dividen en tres grandes ámbitos: prestaciones directas de carácter universal (orientadas a todas las familias, independientemente de sus ingresos, aunque las cuantías puedan estar moduladas en función de la renta); prestaciones directas focalizadas o selectivas (orientadas a las
2 Uno de ellos, recogido también en este mismo número, en el artículo de Domínguez-Olabide (págs. 33-54). 
familias con ingresos inferiores a un umbral determinado); y beneficios fiscales -exenciones, desgravaciones, deducciones, etc.-, que pueden ser reembolsables o no.

- Se han tenido en cuenta también las modalidades y complementos que contemplan estas prestaciones, especialmente en lo que se refiere a las familias numerosas, monoparentales o que tienen hijos/as con discapacidad. También se han tenido en cuenta otras prestaciones menores, como algunas prestaciones por nacimiento, pagos orientados a cubrir los gastos extraordinarios de escolarización, etc.

- Se han analizado los sistemas existentes en la mayor parte de los países de la OCDE, dejando de lado únicamente aquellos países que aun perteneciendo a esta organización son económica, política o culturalmente muy distintos de la CAPV. En general, la información que se ofrece se refiere al conjunto de cada país. Sin embargo, en los países más descentralizados - Canadá, Bélgica, España o Estados Unidos, por ejemplo- el análisis se centra en una provincia o estado concreto, para recoger la aplicación real de las políticas familiares en ese tipo de países. En el caso del Estado español, se recoge la situación de la Comunidad de Madrid - la que la OCDE utiliza como base a la hora de describir el caso españoly la de Euskadi, a partir de la información publicada por las instituciones vascas.

- La mayor parte de la información se ha obtenido de los informes nacionales publicados por la OCDE en su sitio web sobre políticas familiares. La información de la OCDE, en cualquier caso, se ha complementado con otros datos recogidos de las webs de las entidades que gestionan estas ayudas, así como de otras fuentes.

- La descripción de las diferentes prestaciones se centra en las existentes en el año 2020, por lo que no se incluyen los cambios producidos - por ejemplo, en Estados Unidos o Italia- en 2021.

La comparación realizada permite establecer elementos como los siguientes:

- Los modelos de prestaciones de apoyo a las familias que existen en la OCDE, sus características y los países que se integran en cada modelo, especialmente desde el punto de vista de la universalidad / focalización de las prestaciones económicas.

- La combinación que en cada uno de esos modelos se da entre deducciones fiscales reembolsables, deducciones fiscales no reembolsables, prestaciones focalizadas, prestaciones universales moduladas por renta y prestaciones universales no moduladas por renta.

- Los requisitos de acceso a las prestaciones en cuanto a edad, tipología familiar, compatibilidad con otras prestaciones, duración de las ayudas, etc.
- Los sistemas establecidos para el cálculo de las cuantías (escalas de equivalencia, sistemas de estandarización de la renta, consideración de las edades y/o el orden de nacimiento de los hijos/as, etc.).

- Los complementos y modalidades adicionales, especialmente en lo que se refiere a las familias numerosas o monoparentales y en lo que se refiere a situaciones específicas de necesidad (discapacidad, reincorporación escolar, nacimiento, incumplimiento de la obligación de abonar la pensión de alimentos, etc.).

\section{Principales características de las prestaciones por hijo/a a cargo en los países analizados}

\subsection{La articulación del sistema de prestaciones por hijo/a a cargo en los países de la OCDE}

Aunque la práctica totalidad de los países de la OCDE ofrecen algún tipo de prestación económica a las familias con hijos/as para compensar los gastos generales que genera la crianza, los mecanismos utilizados para la provisión de esos apoyos pueden ser muy diferentes. Como se ha señalado en otros trabajos (Bárcena-Martín, Blanco-Arana y Pérez-Moreno, 2015), los diferentes mecanismos destinados a ofrecer apoyo económico a las familias con hijos para compensar los gastos derivados de la crianza pueden ser clasificados en cinco grandes categorías:

- Deducciones fiscales reembolsables, que reducen la cuota tributaria de los progenitores y, además, pueden en su caso ser percibidas como una prestación neta si la deducción supera la deuda tributaria inicial. La percepción de esas cantidades puede ser mensual o anual, mediante un pago único una vez realizada la declaración de la renta.

- Deducciones fiscales no reembolsables, que reducen la tributaria de los progenitores pero no pueden ser utilizadas como una prestación neta si la deducción supera la deuda tributaria inicial.

- Prestaciones directas selectivas o focalizadas, orientadas únicamente a familias con ingresos inferiores a un umbral determinado.

- Prestaciones universales -orientadas al conjunto de las familias con hijos/as- con cuantías moduladas en función de la renta de los progenitores.

- Prestaciones universales no moduladas en función de la renta, orientadas por tanto al conjunto de los progenitores y cuya cuantía no se ve modificada por la renta familiar (aunque sí, en algunos casos, por otros elementos como el número de hijos/as, la edad, etc.). 
En relación con esta clasificación, es necesario señalar cuatro aspectos importantes:

- Las deducciones fiscales (reembolsables o no reembolsables) no son la única herramienta fiscal orientada a las familias con hijos/as. Son también numerosos los países que recurren a otras figuras, como las desgravaciones en la base imponible, los mínimos exentos, la exención de determinadas prestaciones sociales de la base imponible o los coeficientes utilizados para la estandarización de la renta familiar de acuerdo a su tamaño y composición. Este tipo de herramientas no se han tenido en cuenta, en líneas generales, en este análisis en la medida en que solo en contadas ocasiones tienen carácter reembolsable.

- La diferencia entre focalización y universalidad no es siempre nítida. De hecho, algunos modelos selectivos se consideran casi universales, ya que tienen elementos muy tenues de selectividad (es decir, permiten el acceso a la prestación teóricamente selectiva a familias de renta relativamente alta).
- No se tienen en cuenta en este esquema otras prestaciones familiares (como las ayudas a la conciliación por reducción de jornada o excedencia, o los permisos parentales) ni, en general, otras prestaciones de garantía de ingresos que, aunque puedan estar moduladas en función de la presencia de menores de edad en la unidad familiar, no están específicamente orientadas a las familias con hijos/as.

- Por último, el hecho de que un tipo de mecanismo -como las deducciones fiscales reembolsables o las prestaciones directas focalizadas - forme parte de un sistema determinado no implica que juegue un papel importante en ese modelo. En ese sentido, algunas de las prestaciones señaladas juegan un papel residual, ya sea por su cobertura o por las cuantías contempladas, y resultan secundarias frente a otras prestaciones de mayor alcance.

El Cuadro 1 recoge un resumen del tipo de herramienta existente en cada uno de los veintitrés territorios analizados.

\begin{tabular}{|c|c|c|c|c|c|c|}
\hline \multicolumn{7}{|c|}{$\begin{array}{l}\text { Cuadro 1. Herramientas fiscales y prestaciones directas existentes en los países de la OCDE para el apoyo económico a las } \\
\text { familias con hijos/as (2020) }\end{array}$} \\
\hline & & $\begin{array}{l}\text { Deducciones } \\
\text { fiscales } \\
\text { reembolsables }\end{array}$ & $\begin{array}{l}\text { Deducciones } \\
\text { fiscales no } \\
\text { reembolsables }\end{array}$ & $\begin{array}{l}\text { Prestaciones } \\
\text { focalizadas }^{3}\end{array}$ & $\begin{array}{l}\text { Prestaciones } \\
\text { universales } \\
\text { (con renta) }\end{array}$ & $\begin{array}{c}\text { Prestaciones } \\
\text { universales } \\
\text { (sin renta) }\end{array}$ \\
\hline \multirow{6}{*}{$\begin{array}{l}\text { Centro de } \\
\text { Europa }\end{array}$} & Francia & - & $\sqrt{4}^{4}$ & $\sqrt{ }$ & $\sqrt{ }$ & - \\
\hline & \begin{tabular}{|l|} 
Alemania \\
\end{tabular} & $\sqrt{5}$ & - & $\sqrt{ }$ & - & $\sqrt{ }$ \\
\hline & Austria & - & $\sqrt{6}$ & $\sqrt{ }$ & - & $\sqrt{ }$ \\
\hline & Países Bajos & $\sqrt{ }$ & - & $\sqrt{ }$ & - & $\sqrt{ }$ \\
\hline & Bélgica (Valonia) & - & $\sqrt{7}$ & - & $\sqrt{ }$ & - \\
\hline & Suiza (Ginebra) & - & $\sqrt{8}$ & - & - & $\sqrt{ }$ \\
\hline \multirow{2}{*}{$\begin{array}{l}\text { Países } \\
\text { anglosajones }\end{array}$} & Reino Unido & $\sqrt{ }$ & - & $\sqrt{ }$ & - & $\sqrt{ }$ \\
\hline & \begin{tabular}{|l|} 
Irlanda \\
\end{tabular} & $\sqrt{ }$ & - & $\sqrt{ }$ & - & $\sqrt{ }$ \\
\hline \multirow{5}{*}{$\begin{array}{l}\text { Sur de } \\
\text { Europa }\end{array}$} & Italia & $\sqrt{ }$ & $\sqrt{ }$ & $\sqrt{ }$ & $\sqrt{ }$ & - \\
\hline & \begin{tabular}{|l|} 
Portugal \\
\end{tabular} & $\sqrt{ }$ & - & $\sqrt{ }$ & - & - \\
\hline & Grecia & - & $\sqrt{ }$ & $\sqrt{ }$ & - & - \\
\hline & España (Madrid) & $\sqrt{ }$ & $\sqrt{ }$ & $\sqrt{9}$ & - & - \\
\hline & España (Euskadi) & - & $\sqrt{ }$ & - & $\sqrt{ }$ & - \\
\hline \multirow{4}{*}{ Norte de Europa } & Noruega & - & $\sqrt{10}$ & $\sqrt{ }$ & - & $\sqrt{ }$ \\
\hline & Suecia & - & - & - & - & $\sqrt{ }$ \\
\hline & \begin{tabular}{|l} 
Dinamarca \\
\end{tabular} & - & $\sqrt{11}$ & $\sqrt{ }$ & $\sqrt{ }$ & - \\
\hline & Finlandia & - & - & - & - & $\sqrt{ }$ \\
\hline \multirow{2}{*}{$\begin{array}{l}\text { Este de } \\
\text { Europa }\end{array}$} & Polonia & $\sqrt{ }$ & - & $\sqrt{ }$ & - & $\sqrt{ }$ \\
\hline & Rep. Checa & $\sqrt{ }$ & - & $\sqrt{ }$ & - & - \\
\hline \multirow{4}{*}{ Otros } & Canadá (Quebec) & - & - & - & $\sqrt{ }$ & - \\
\hline & Japón & - & $\sqrt{ }$ & - & $\sqrt{ }$ & - \\
\hline & Nueva Zelanda & $\sqrt{ }$ & - & - & - & - \\
\hline & Estados Unidos (Michigan) & $\sqrt{ }$ & $\checkmark$ & $\sqrt{ }$ & - & - \\
\hline
\end{tabular}

Fuente: Elaboración propia a partir de los informes nacionales de la OCDE.

${ }^{3}$ En ocasiones se consideran en esta categoría complementos específicos de las prestaciones universales destinadas a familias con ingresos inferiores a un umbral determinado.

${ }^{4}$ Se trata de una reducción de la base imponible.

5 Incompatible con la prestación directa.

${ }^{6}$ Desde 2019.

7 Se trata de una reducción de la base imponible.

${ }^{8}$ Se aplica una reducción de la base imponible y posteriormente una deducción en la cuota.

9 Hasta 2020, con la integración de la prestación por hijo a cargo (PFHC) de la Seguridad Social en el ingreso mínimo vital.

${ }^{10}$ Se trata de una reducción de la base imponible.

${ }^{11}$ Se trata de una reducción de la base imponible. 
La primera de las cuestiones que se observa en el cuadro es la diversidad en cuanto al número de herramientas aplicadas en cada país y, en ese sentido, a la mayor o menor complejidad del modelo vigente en cada uno de ellos: en efecto, hay países, como Finlandia o Suecia, que cuentan con un solo tipo de prestación (universal sin criterio de renta, en ambos casos); en el otro extremo, Italia ${ }^{12} 0$ España combinan hasta cuatro tipos de prestaciones diferentes. Sin llegar a tales extremos, parece claro que algunos modelos han desarrollado modelos más integrales o unificados, mientras que otros han apostado, en general por razones históricas, por una mayor fragmentación o categorización.

En todo caso, los datos de la tabla indican los siguientes elementos de interés:

- 17 de los 23 países o regiones analizados disponen de prestaciones universales o casi universales. En estos sistemas, la prestación puede ser percibida por todas las familias independientemente de su nivel de ingresos, aunque la cuantía concreta de la prestación sí pueda estar modulada en función de la renta.

- En 10 de esos 17 casos, además, se trata de prestaciones universales no moduladas en función del nivel de renta (Alemania, Austria, Países Bajos, Suiza, Reino Unido, Irlanda, Noruega, Suecia, Finlandia y Polonia). Es decir, las familias no solo acceden a la prestación independientemente de su nivel de renta, sino que la prestación es además de la misma cuantía para todas las familias y su renta no se tiene en cuenta para determinar el importe de la prestación. En los otros siete casos -Francia, Bélgica, Italia, Euskadi, Dinamarca, Quebec y Japón- la prestación es universal, pero se modula en función de la renta familiar, aplicándose en algunos casos un sistema de estandarización o equivalencia.

- 15 de los 23 países analizados disponen de prestaciones selectivas, orientadas únicamente a las familias con ingresos inferiores a un umbral determinado. En diez de esos dieciséis casos -Alemania, Austria, Canadá (Quebec), Francia, Países Bajos, Irlanda, Italia, Japón, Noruega y Polonia-, la prestación focalizada convive con una prestación universal. En cinco casos -Madrid, Grecia, Estados Unidos, Portugal y Chequia- la prestación focalizada es la única prestación directa existente.

- 20 de los 23 países analizados cuentan con deducciones fiscales o desgravaciones de algún tipo para las familias con hijos/as. Los países 0 regiones que no cuentan con figuras de este tipo son Quebec (Canadá), Finlandia y Suecia.

${ }^{12}$ Como se ha señalado previamente, Italia está en vías de modificar su sistema, reduciendo la actual fragmentación mediante la creación de una prestación única de carácter universal.
- De los 20 países que contemplan deducciones fiscales de apoyo a las familias con hijos/as, once han recurrido a las deducciones reembolsables, de forma que si la deuda tributaria es inferior a la deducción, la diferencia se abona como prestación neta a los/as contribuyentes, siempre que cumplan el resto de los requisitos de acceso. En los nueve casos restantes las deducciones fiscales no son de carácter reembolsable, con lo que no se benefician de ellas las familias con menor renta.

- Son pocos los países que basan su modelo de apoyo a las familias únicamente en las deducciones fiscales. Cabría señalar en ese sentido el modelo norteamericano y el alemán, donde la deducción fiscal y la prestación universal son alternativas (ha de optarse solo por una de ellas), así como el neozelandés.

Esta clasificación permite agrupar los países analizados en los siguientes grupos:

- Sistemas básicamente articulados en torno a una sola prestación de carácter universal, modulada o no en función de la renta: Finlandia, Suecia, Noruega y Reino Unido (tras la derogación de los créditos fiscales para familias y para trabajadores/as pobres).

- Sistemas que combinan deducciones fiscales y prestaciones universales: Bélgica (Valonia), Dinamarca y Suiza.

- Sistemas que combinan prestaciones universales y selectivas, sin deducciones: Japón y Quebec (Canadá).

- Sistemas que combinan deducciones fiscales, prestaciones selectivas y prestaciones universales: Alemania, Austria, Euskadi, Francia, Países Bajos, Irlanda, Italia y Polonia.

- Sistemas que combinan deducciones fiscales -en general no reembolsables-y prestaciones selectivas: Madrid (España), Grecia, Portugal, Chequia y Estados Unidos.

- Sistemas que solo contemplan deducciones fiscales: Nueva Zelanda.

Puede decirse, por tanto, que los países del norte de Europa, con sistemas de protección social más desarrollados, tienden en general a basarse únicamente en prestaciones universales. Los países del centro tienden por el contrario a combinar un mayor número de prestaciones -deducciones fiscales, prestaciones focalizadas y universales-, mientras que los del sur se apoyan en una combinación de deducciones fiscales teóricamente universales - pero que no son reembolsables y no llegan a las familias de menor renta- y prestaciones focalizadas orientadas a las familias de bajos o muy bajos ingresos.

También se observan casos relativamente singulares (como Japón, Estados Unidos o Nueva Zelanda) y casos de países que, como Italia, se sitúan 
en un grupo en el que no suelen habitualmente ser ubicados cuando se realizan este tipo de clasificaciones en materia de protección social.

\subsection{Otros elementos vinculados al diseño de las prestaciones}

Junto con la articulación general del paquete de prestaciones orientado a las familias con hijos/as, es conveniente también repasar, aunque sea de forma somera, otros elementos relacionados con el diseño de las prestaciones -ya sean directas o provistas mediante el sistema tributario- en lo que se refiere a los criterios de acceso, la determinación de las cuantías, la existencia de complementos y modalidades, la compatibilidad con otras prestaciones, los mecanismos de condicionalidad diferentes a del nivel de ingresos y la consideración de las cuestiones relacionadas con la diversidad de las composiciones familiares.

\section{a. Criterios de acceso}

Los criterios de acceso que se establece en el caso de las prestaciones analizadas en este capítulo tienen que ver fundamentalmente con el número y la edad de los hijos/as, aunque también se establecen algunos requisitos de acceso o percepción de estas prestaciones vinculadas a otros aspectos, como la escolarización de los hijos/as o la participación en el mercado de trabajo, en el marco de las políticas de activación.

En lo que se refiere al número de hijos/as, la mayor parte de las prestaciones se ofrecen a todas las familias con hijos/as que cumplan los requisitos de renta, en el caso de las prestaciones focalizadas o moduladas en función de la renta. Destaca en este caso la excepción francesa, que no incluye en sus principales prestaciones a las familias con un solo hijo/a.

En lo que se refiere a la edad, la mayoría de las prestaciones analizadas cubren a los hijos/as menores de edad, así como a los que aun siendo mayores de 18 años no tienen ingresos propios, viven en el domicilio familiar $\mathrm{y} / \mathrm{o}$ cursan estudios reglados.

\section{b. Determinación de las cuantías}

La determinación de las cuantías es uno de los elementos más característicos de cada sistema, y en los que existen mayores diferencias. Los modelos que existen son, básicamente, los siguientes:

- Cuantías uniformes por todos los hijos/as, independientemente de su edad o número de orden.

- En Irlanda la prestación no tiene en cuenta los ingresos de la unidad familiar ni la edad de los hijos/as, y crecen de forma proporcional en función del número de hijos, a partir de una cuantía básica de 140 euros mensuales. De esta forma, las familias con dos hijos/as perciben 280 euros, las familias con tres hijos/as, 420, y así sucesivamente.

- En Noruega, la cuantía de la prestación es de 84 euros, independientemente de la edad, el número de hermanos/as o la renta familiar.

- En Polonia, la cuantía de la prestación asciende a 109 euros mensuales y es independiente tanto del número de hijos/as, como de su edad y de la renta familiar.

- Cuantías diferentes en función de la edad. Cabe distinguir dos opciones:

- Incremento de las cuantías a medida que crece la edad del hijo/a. En Alemania, Austria o Países Bajos, por ejemplo, las cuantías crecen según se pasa de un tramo de edad a otro. En Francia se aplica un complemento a los mayores de 14 años.

- Decremento de las cuantías a medida que crece la edad del hijo/a. En Portugal o Dinamarca las cuantías se reducen según crece la edad de los hijos/as.

- Cuantías diferentes en función del número de orden y/o el número de hijos. Aquí también cabe distinguir dos casos:

- Incremento de las cuantías por hijos/as a medida que crece su número. En el caso austriaco, además de aumentar con la edad, la cuantía de la prestación es más elevada a medida que se avanza en el número de hijos/as ${ }^{13}$. En el caso alemán, se conceden 204 euros al mes para el primer y segundo hijo/a, 210 euros al mes para el tercer hijo/a y 235 euros al mes para el cuarto y siguientes. Lo mismo ocurre en el caso de Finlandia, Países Bajos ${ }^{14} 0$ Euskadi, donde la deducción fiscal pasa de 603 euros por el primer hijo/a a 1.946 por el quinto. En Grecia, la cuantía para el tercer hijo/a crece considerablemente en relación con la correspondiente a los dos primeros. En el caso de Ginebra (Suiza), la cuantía asciende a 284 euros mensuales para los dos primeros hijos/as y a 378 en el caso de los siguientes.

- Decremento de las cuantías a medida que crece el número de hijos/as. En el caso británico, por ejemplo, la prestación por el primer hijo/a es de 89 euros, mientras que para los demás la cuantía es de 54 euros. En el caso italiano, aunque los cambios no son lineales, la cuantía de cada hijo/a adicional se va reduciendo progresivamente, mientras que en Portugal la del primer hijo/a es sustancialmente más elevada que las de los demás. El caso sueco es

${ }^{13}$ Así, un hijo/a solo/a de o a 3 años recibe por ejemplo 115 euros, mientras que tres hijos/as mayores de 19 años recibirían, cada uno/a, 182,5 euros.

${ }^{14}$ Es significativo en cualquier caso que en Holanda la cuantía por hijo/a de la prestación universal crece con el número de hijos/as, mientras que en el caso de la prestación selectiva se reduce. 
peculiar, ya que la cuantía de las prestaciones tiene forma de U: la prestación para un solo hijo/a asciende a 113 euros mensuales (15.000 coronas suecas anuales); a partir de esa cantidad, la cuantía adicional para el segundo hijo/a es de 13 euros mensuales para el segundo hijo/a, 52 para el tercero, 91 para el cuarto y 113 para el quinto y siguientes.

A esas diferencias se suman otras relacionadas con los ingresos de la familia, lo que añade un plus de complejidad a algunos de los sistemas analizados. Por citar los casos más extremos, en Estados Unidos o Italia la cuantía se reduce progresivamente en función de los ingresos, mientras que Euskadi, Portugal o Japón contemplan más de media docena de cuantías diferentes (en función de la renta, la edad y el número de hijos/as). En sentido contrario, como se ha dicho, en Polonia, Irlanda o Noruega la cuantía es la misma independientemente de la edad, el número de hijos/as o la renta familiar.

\section{c. Existencia de complementos y modalidades}

Los sistemas de prestaciones analizados contemplan, tanto en sus modalidades universales como selectivas $-\mathrm{y}$ tanto en las prestaciones directas como en las deducciones fiscales-, muy diversas modalidades 0 complementos dirigidos a dar respuesta a situaciones específicas de necesidad. En algunos casos se trata de prestaciones o modalidades diferentes, mientras que en otros se trata de complementos a las cuantías previamente determinadas. Las situaciones contempladas son las siguientes ${ }^{15}$ :

- Discapacidad. Al margen de las prestaciones que puedan corresponder en el marco de los sistemas de atención a la dependencia, algunos países contemplan complementos o modalidades en sus prestaciones familiares orientadas a compensar los gastos extraordinarios que implica la discapacidad.

- En Valonia, en el caso de las familias con algún progenitor con discapacidad, se conceden 10 euros adicionales por hijo/a en caso de ingresos brutos inferiores a 30.984 euros.

- En Polonia, la prestación selectiva por hijo/a a cargo se extiende hasta los 24 años, frente a los 18 habituales, en el caso de los hijos/a con discapacidad. En el caso de la prestación selectiva, esta se incrementa entre 17 y 34 euros adicionales si alguno de los miembros de la familia tiene una discapacidad.

- El modelo de tax credits británico, en proceso de derogación, contemplaba una serie de complementos específicos para los hijos/as a cargo con discapacidad.

${ }^{15}$ Dos de las necesidades más habitualmente contempladas -el tamaño de la familia, especialmente en el caso de las familias numerosas, y la renta, especialmente en el caso de las familias de rentas bajas- no se recogen en este epígrafe, pues se ha hecho referencia e ellas en los anteriores.
- En Canadá, en el caso de que alguno de los menores a cargo tenga una discapacidad, se abona un suplemento adicional de 110 euros mensuales.

- En España, la prestación por hijo/a a cargo está destinada a familias con hijos/as menores de 18 años, así como mayores de edad -siempre que convivan en el domicilio familiar-con discapacidad. Además, existe en el impuesto sobre la renta una deducción por persona con discapacidad a cargo que asciende a 1.200 euros anuales por cada descendiente 0 ascendiente con discapacidad.

- En Euskadi, en el supuesto de que el hijo o la hija que origina la ayuda tenga reconocida una discapacidad de porcentaje igual o superior al $33 \%$ o una situación de dependencia, las cuantías previstas por la prestación universal se multiplican por dos.

- Monoparentalidad. La monoparentalidad es una de las situaciones específicas que con más frecuencia se contempla.

- En el caso de Francia la llamada Allocation de soutien famillialle, orientada a las familias monoparentales y a las familias acogedoras con hijos/as menores de 20 años, contempla una cuantía por hijo/a de 115 euros.

- En Países Bajos, las familias monoparentales que acceden a la prestación selectiva por hijo/a a cargo reciben un complemento adicional de 3.139 euros anuales.

- En Valonia, Bélgica, se aplica a las familias monoparentales un complemento de entre de entre 10 y 20 euros adicionales por hijo/a, en función de los tramos de ingresos.

- Irlanda cuenta con el denominado One-parent family payment, que se dirige a todas las personas solas menores de 66 con al menos un menor de siete años a cargo, y con otra prestación para familias monoparentales en situación de desempleo e hijos/as de siete a trece años de edad (jobseekers trasnsitional payment) que asciende a 800 euros y una cantidad adicional de 125 por cada hijo/a. Contempla también deducciones fiscales para familias monoparentales y para personas viudas con hijos/as.

- En Noruega, en el caso de las familias monoparentales al número real de hijos/as se le añade otro adicional, por lo que la cuantía de la prestación se incrementa en cualquier caso en 84 euros. Además, Noruega dispone de una prestación selectiva y de carácter contributivo, sujeta a tributación y orientada a las familias monoparentales, denominada Overgansgstonad. Es necesario haber cotizado a la Seguridad Social durante al menos un periodo previo de tres años. La prestación solo puede percibirse durante un máximo de tres años y se dirige a familias monoparentales con hijos/as menores de ocho años, salvo excepciones. Por otra parte, la percepción de la prestación exige la participación en 
determinadas actividades de formación y orientación laboral a partir de que el hijo/a más pequeño cumpla un año de edad.

- Dinamarca concede un subsidio, denominado Bornetiskuld, destinado a los progenitores solos con hijos/as menores de 18 años. Tiene una cuantía básica de 62 euros mensuales por hijo/a, complementada con otros 63 euros anuales para el conjunto de la familia.

- En Finlandia, en el caso de las familias monoparentales, se añade a la prestación universal por hijo/a una cantidad adicional de 63,3 euros por cada hijo/a.

- La prestación selectiva polaca contempla un complemento de monoparentalidad de 42 euros mensuales por hijo/a, con un máximo de 85 euros por familia.

- En Canadá, las cuantías correspondientes a la prestación básica se multiplican en el caso de las familias monoparentales por entre 1,1 y 1,4 dependiendo del número de hijos/as y de la renta familiar.

- En Euskadi, la monoparentalidad se tiene en cuenta tanto a la hora de calcular la renta estandarizada que determina la cuantía de las prestaciones universales como a la hora de establecer una desgravación adicional en el caso de realizar la declaración de la renta en su modalidad conjunta.

- Nacimiento. Una decena de países contemplan una prima o prestación específica por nacimiento.

- En Francia, la Prime à la naissance ou à l'adoption de la Prestation d'Accueil pour jeune enfant (PAJE) es una prestación selectiva, condicionada al nivel de ingresos, por nacimiento o adopción. La prestación se abona durante los tres primeros años de vida y oscila entre 85 y 171 euros en función de los ingresos familiares, el número de hijos/as con derecho a la ayuda y el número de personas adultas perceptoras de ingresos.

- En Inglaterra y Gales existe una prestación denominada Sure Start Maternity Grant dirigida a cubrir los gastos derivados del nacimiento para familias que ya perciben otras prestaciones sociales, $y$ que no se beneficien del permiso de maternidad de la Seguridad Social. Se trata de un solo pago de 541 euros (50o libras esterlinas).

- Valonia contempla una prima de nacimiento o adopción de 1.122 euros por hijo/a.

- Italia cuenta con una prestación selectiva por nacimiento - bonus bebé o assegno di natalitá-que se paga de forma mensual durante los doce primeros meses de vida del niño/a, con cuantías diferentes en función de la renta. prestaciones específicas por nacimiento, que oscilan entre 950 y 2.840 euros, dependiendo del número de hijos/as y del cantón de residencia. En el caso del cantón de Ginebra, la prestación asciende a 1.894 euros.
- La prestación selectiva polaca contempla un complemento extraordinario de 218 euros con motivo de cada nacimiento.

- Adelanto de pensiones de alimentos. Muchos de los países analizados, especialmente los nórdicos, contemplan prestaciones específicas para adelantar las pensiones de alimentos de los cónyuges que no satisfacen esas obligaciones.

- Noruega cuenta con otra prestación selectiva para familias monoparentales orientada a adelantar la pensión de alimentos que no es abonada por el otro cónyuge. El pago de la prestación se calcula en función de tres tramos, a partir de la renta de la unidad familiar: 69,8 euros en el caso de la cuantía reducida, 104 en el caso de la cuantía estándar y 139,6 en el caso de la cuantía máxima. La cuantía máxima se abona a familias con ingresos inferiores a 23.588 euros y el derecho a la prestación se pierde a partir de ingresos superiores a 44.700 euros, aunque los límites pueden variar si la persona que percibe la prestación convive con otra persona diferente del otro progenitor.

- Suecia cuenta con una prestación orientada a compensar a los padres o madres solos que no reciben una pensión de alimentos por parte del otro progenitor. La prestación se abona a los progenitores solos con hijos/as de hasta 16 años (o hasta 20, en caso de que estén escolarizados).

- En Dinamarca, los progenitores solos reciben de la Administración una cuantía anual de 2.163 euros por hijo/a, que se reclaman posteriormente al otro progenitor/a.

- Finlandia dispone de una prestación - también no contributiva y universal- destinada a compensar a los cónyuges solos que no reciben la pensión de alimentos que corresponde pagar al otro cónyuge.

- Japón dispone de una prestación selectiva orientada a las familias monoparentales en las que el cónyuge a cargo de los menores no recibe la pensión de alimentos por parte del otro cónyuge. La cuantía básica de la prestación es de 361 euros. En el caso de un segundo hijo/a, la cuantía se incrementa en 88,4 euros y a partir del tercero en 51,7. Como se ha señalado, la prestación es selectiva: si, dependiendo del número de hijos/as, la familia se sitúa por debajo de un primer umbral, se percibe la cuantía íntegra. Si se sitúan entre se umbral y el siguiente, se percibe una prestación reducida en función de los ingresos, y si, finalmente, los ingresos se sitúan por encima del segundo umbral, desaparece el derecho a percibir la prestación.

- Gastos extraordinarios de escolarización. Diversos países disponen de prestaciones vinculadas al inicio del año escolar.

- Francia cuenta, por ejemplo, con la llamada allocation rentrée scolaire para familias con 
hijos/as de 6 a 16 años de edad que cumplen los requisitos de acceso a las prestaciones familiares universales.

- En Austria, las familias con hijos/as de 6 a 15 años de edad reciben cada año (en septiembre) una prestación de 100 euros por hijo/a para sufragar los gastos derivados del inicio del curso escolar.

- Valonia contempla primas específicas con motivo de la reanudación del curso escolar de entre 20 y 80 euros según la edad del menor.

- En Portugal, las familias con menores ingresos de todas las que acceden a la prestación selectiva reciben además una prestación mensual extraordinaria en el mes de septiembre para dar respuesta a los gastos extraordinarios de escolarización.

- La prestación selectiva polaca concede 21,8 euros adicionales por hijo/a en edad de escolarización obligatoria al inicio del curso escolar.

- En Canadá, se concede un complemento de 68 euros en el mes de septiembre por cada beneficiario de la prestación básica de entre $4 \mathrm{y}$ 16 años con motivo del inicio del curso escolar.

\section{d. Organismos encargados de la gestión, niveles de descentralización y sistemas de financiación}

Los organismos encargados de la gestión y los niveles de la Administración que financian y gestionan estas prestaciones dependen en gran medida del diseño del conjunto del sistema institucional de cada país. En todo caso, en la mayor parte de los países analizados las prestaciones son financiadas y abonadas por el sistema de la Seguridad Social, si bien la diferencia entre la Seguridad Social y el resto de los organismos que intervienen en el campo de la protección social no es siempre muy clara. Frente a la gestión por parte de la Seguridad Social, algunos países han atribuido la gestión de estas prestaciones a organismos que combinan la función recaudatoria con la gestión de prestaciones directas.

Se resumen a continuación los sistemas de gestión que se han considerado más significativos:

- En Francia, las prestaciones familiares son financiadas y gestionada por las Caisses d'Allocations Familialles, de ámbito departamental, encargadas también de la gestión de otras prestaciones económicas de garantía de ingresos y de vivienda.

- En Alemania, las prestaciones son gestionadas por las Famillienkasse, dependientes del Ministerio de Empleo, desplegadas a nivel estatal y que gestionan también otras prestaciones y servicios de apoyo en el ámbito de la juventud, el desempleo, etc.

- En Italia, el Assegno per il Nucleo Familiare (ANF) depende de la Seguridad Social (Istituto
Nazionale della Previdenza Sociale), que gestiona también las pensiones y las prestaciones por desempleo.

- En Portugal, el Abono de família para crianças e jovens es gestionado por la Seguridad Social, responsable del pago de las principales prestaciones económicas portuguesas.

- En Finlandia, la gestión de la prestación corresponde a Kela, el instituto finlandés de la Seguridad Social que gestiona también las pensiones, los subsidios por desempleo, las ayudas a la vivienda y las prestaciones de garantía de ingresos.

- En Bélgica, la gestión de estas prestaciones está delegada en una serie de cajas públicas y privadas de prestaciones familiares, de tal forma que las personas usuarias pueden elegir entre más de una opción para la gestión de sus ayudas. Actualmente, por ejemplo en la región de Valonia, existen cinco cajas privadas y una caja pública encargadas de gestionar únicamente las prestaciones familiares.

- En Suiza, cada rama de la Seguridad Social está gestionada por una entidad diferente. La gestión de las prestaciones por hijo/a a cargo corresponde a las cajas cantonales de familia.

- En Países Bajos, la gestión de estas prestaciones corresponde a la Sociale Verzekeringsbank (SVB), que gestiona también las pensiones y las prestaciones por dependencia.

- En el Reino Unido, la gestión corresponde al Departamento de Hacienda (Her Majesty's Revenue and Customs), que se encarga tanto de la recaudación de determinados impuestos y de las cotizaciones a la seguridad social como del pago de ciertas prestaciones económicas.

- En Estados Unidos y Nueva Zelanda, la gestión corresponde al sistema fiscal. En el caso estadounidense, aunque existen también deducciones fiscales estatales, el EITC y el CTC se gestionan desde el Internal Revenue Service (IRS). En el caso neozelandés, la gestión de estas ayudas corresponde al Inland Revenue, responsable tanto de la recaudación de impuestos como de la gestión de determinadas prestaciones económicas.

En lo que se refiere a la financiación del sistema, el modelo más singular es el suizo, ya que las prestaciones se basan en un sistema de cotizaciones salariales y empresariales.

En cuanto al grado de descentralización, se trata en general de prestaciones de carácter estatal, con la salvedad de Bélgica, Suiza, España y Canadá. Francia y Alemania basan por su parte sus sistemas en cajas familiares desplegadas a nivel de cada departamento (en Francia) o land (en Alemania). En el Estado español -dejando de lado el caso atípico de Euskadi y Navarra- las prestaciones señaladas son de competencia estatal, si bien las comunidades autónomas desarrollaron en su momento 
prestaciones por hijo/a a cargo que fueron en general derogadas tras la crisis.

\section{e. Otras cuestiones: compatibilidad con otras prestaciones, condicionalidad y diversidad familiar}

Existen al menos otros tres elementos de interés en relación con el diseño de estas ayudas. El primero de ellos tiene que ver con la compatibilidad entre las prestaciones infantiles señaladas y otras prestaciones selectivas, como los subsidios por desempleo, las prestaciones de vivienda o las prestaciones de garantía de ingresos. El análisis realizado no se ha centrado en esta cuestión, ya que las fuentes consultadas no recogen siempre en detalle información al respecto. En todo caso, puede decirse que en la mayor parte de los ocasiones las prestaciones universales señaladas no son incompatibles con la percepción de ese tipo de prestaciones, que a menudo incluyen complementos o cuantías adicionales derivadas de la presencia de menores a cargo. En el caso de las prestaciones selectivas por hijo/a, su compatibilidad con las prestaciones selectivas más genéricas (por desempleo o de garantía de ingresos) es menos habitual, pero no infrecuente.

En todo caso, algunos países establecen figuras como el benefit cap británico, mediante el cual se establece un límite a la cuantía total que una familia puede obtener a través de las diversas prestaciones económicas públicas.

El segundo elemento de interés tiene que ver con la condicionalidad de las prestaciones: a diferencia de lo que ocurre en el caso de las prestaciones por desempleo o de garantía de ingresos, la mayor parte de estas prestaciones no imponen condiciones de conducta o comportamiento, más allá de las condiciones de acceso (edad, renta, etc.). Hay, sin embargo, tres excepciones a esa regla general:

- En muchos países, la extensión de la prestación más allá de los 18 años (o, incluso, 16 en algunos países) se condiciona a la realización de estudios reglados por parte de esos hijos/as.

- En otros casos, menos frecuentes, la percepción de la prestación se vincula al desempeño de una actividad laboral por parte de algunos de los progenitores, en la lógica de la activación y de los llamados in work benefits ${ }^{16}$. Existen prestaciones de este tipo en Nueva Zelanda, Dinamarca, Estados Unidos, Irlanda o Italia. El caso más extremo sería el de Estados Unidos, donde los progenitores que no trabajan no pueden beneficiarse de la mayor parte de las prestaciones por hijo/a a cargo (Bitler et al., 2018).

${ }^{16}$ Estas prestaciones están orientadas a las personas que trabajan, y por lo general buscan estimular el acceso al empleo de las personas perceptoras de prestaciones de garantía de ingresos, reducir la llamada trampa de la pobreza y/o proteger a los trabajadores de bajos salarios.
Cabe señalar por último que, aunque no es una cuestión que se haya analizado en detalle, las prestaciones por hijo/a a cargo se conceden en general con independencia del tipo de unión familiar establecida (matrimonio, pareja de hecho, ausencia de vínculos legales, etc.) o del sexo de los progenitores. Se han identificado, con todo, algunos $\operatorname{casos}^{17}$ en los que se da un tratamiento diferente a las personas viudas - frente a otras formas de monoparentalidad- $y$ otros en lo que la figura materna tiene, frente a la paterna, un tratamiento específico ${ }^{18}$.

\section{El impacto de las prestaciones familiares}

Como se ha señalado en la introducción, el objetivo de este apartado es repasar la evidencia disponible sobre el impacto de las prestaciones por hijo/a a cargo, cuyo diseño y funcionamiento se ha analizado en el apartado anterior. Para ello, se han analizado los estudios y revisiones de la literatura que han intentado determinar qué impacto tienen este tipo de prestaciones en cuatro aspectos específicos: la fecundidad, el acceso de los padres y las madres al mercado de trabajo, el bienestar infantil (en relación con aspectos como la salud o el rendimiento académico), y la reducción de las tasas de pobreza infantil, teniendo también en cuenta el impacto de las carencias económicas sobre el desarrollo infantil. Se analizan además algunos trabajos en los que se han investigado cuestiones más relacionadas con el diseño de estas prestaciones, especialmente en lo que se refiere a dos aspectos: por una parte, la provisión de estos apoyos mediante ayudas directas o mediante herramientas fiscales y, por otra, el grado de universalidad o focalización de las ayudas.

La revisión que se ha realizado no tiene carácter exhaustivo y pretende fundamentalmente contextualizar el análisis que se lleva a cabo en las páginas siguientes. A la hora de interpretar los resultados, se debe tener en cuenta además que la literatura revisada no siempre se centra exclusivamente en el impacto de las prestaciones que se analizan en este estudio: por una parte, algunos de los estudios revisados analizan el impacto del conjunto de las políticas familiares sobre las variables consideradas, aunque en esta revisión se ha intentado extraer la información relativa a las prestaciones económicas por hijo/a a cargo, dejando de lado otros servicios o prestaciones (prestaciones para la conciliación, permisos parentales, atención infantil, etc.). Por otra parte, algunos de los estudios revisados analizan el impacto del conjunto de las prestaciones económicas a las que tienen acceso las familias, incluyendo las de garantía de ingresos,

\footnotetext{
${ }_{17}$ Por ejemplo en Irlanda o Francia.
}

${ }^{18}$ Por ejemplo, Canadá, Irlanda o Dinamarca abonan sus prestaciones, en principio, a las madres. En algunos casos, como la deducción fiscal establecida en España, las destinatarias solo pueden ser las madres trabajadoras. En sentido contrario, una de las condiciones para la percepción del Assegno dei comuni italiano es que la madre no realice un trabajo remunerado. 
desempleo, etc., y no solo las prestaciones por hijo/a a cargo. En este caso, estas prestaciones no se tienen en cuenta porque el objetivo del estudio es analizar el impacto de las prestaciones familiares y no el del conjunto de las prestaciones sociales.

Es también necesario tener en cuenta que la literatura revisada analiza prestaciones por hijo/a a cargo con características muy diferentes (en algunos casos, universales y, en otros, focalizadas; a veces concebidas como ayudas directas y otras como deducciones fiscales; en ocasiones de cuantía importante y en otros casos de cuantía más reducida, etc.). Esa variabilidad hace que sea difícil extraer conclusiones universalmente válidas de esta revisión, si bien, como se señala en el apartado de conclusiones, sí es posible extraer del análisis realizado algunas conclusiones claras y generalizables sobre el impacto de estas prestaciones sobre los elementos analizados.

\subsection{Impacto de las prestaciones económicas sobre la pobreza y el bienestar infantil}

Antes de hacer referencia al impacto de las prestaciones económicas infantiles sobre la reducción de la pobreza infantil y la mejora del bienestar de niños y niñas, cabe hacer en primer lugar referencia al impacto a corto, medio y largo plazo de las carencias económicas sobre el desarrollo infantil. Desde ese punto de vista, existe suficiente evidencia disponible que apunta a la idea de que "el dinero importa", es decir, que el nivel de recursos económicos de las familias tiene un impacto directo en el desarrollo de los niños/as en el corto, medio y largo plazo.

Tal y como explican Gennetian et al. (2010), hasta la fecha la relación entre ingresos y desarrollo infantil se ha interpretado de dos maneras: por una parte, se tiende a pensar que la carencia de ingresos incrementa el estrés parental, lo que perjudica el desarrollo infantil; por otra parte, desde una óptica más basada en la inversión educativa, se tiende a pensar que la disponibilidad de ingresos permite a las familias proveer a sus hijos e hijas de cuidados de mayor calidad y de una mayor inversión en su educación. Si en un caso el énfasis se pone en la reducción de las habilidades parentales que representa la carencia de ingresos, en el otro se hace hincapié en la carencia de medios materiales para procurar un desarrollo adecuado. Para estos autores la evidencia científica disponible no permite aclarar cuál de estos enfoques resulta el más adecuado y, de hecho, no se puede asegurar si los peores resultados cosechados por los niños pobres en su vida adulta -sobre lo cual sí hay consenso- se relacionan causalmente con la carencia de ingresos o, por el contrario, con otros factores concomitantes, como la monoparentalidad o los bajos niveles educativos. En cualquier caso, la mayor parte de la evidencia disponible apunta a que, al menos en las familias que han vivido situaciones persistentes de pobreza, la mejora de los ingresos familiares se relaciona de forma clara con unos resultados más positivos en la edad adulta.

En ese sentido, uno de los principales expertos españoles en la materia, Pau Marí-Klose (2019), señala que "las situaciones de privación material en la infancia entrañan pocas veces experiencias extremas, pero acarrean desventajas relativas que pueden ser muy profundas y tener importantes implicaciones. Desventajas para participar en su sociedad en condiciones elementales que aseguren una vida adecuada conforme a los parámetros considerado normales por la inmensa mayoría de la población, así como para garantizar que estos niños y niñas puedan desarrollar sus facultades, talentos y capacidades libres de hándicaps que se lo impidan [...]". "La experiencia de la adversidad en la infancia", concluye Marí-Klose, "no es una forma de malestar como cualquier otra. Es una experiencia crítica que influye sobre procesos nucleares de la vida de las personas: su educación, su salud, su predisposición a desarrollar hábitos perjudiciales, su inserción laboral, etc.".

En sentido parecido, una reciente revisión sobre el impacto de la situación económica familiar en el bienestar infantil (Cooper y Stewart, 2017) pone de manifiesto que las carencias económicas durante la infancia tienen impactos claros en cuanto a las capacidades cognitivas, el estado de salud, el desarrollo socioemocional y el rendimiento académico de los niños y niñas que crecen en familias pobres. Las conclusiones de la revisión ponen de manifiesto que las carencias económicas son la causa directa de los peores resultados que los niños/as pobres registran en estos ámbitos en relación con los niños/as que han crecido en situaciones económicas más favorecidas, y, por tanto, que una mejora en sus niveles de ingresos reduciría en buena medida las diferencias entre los niños/as pobres y el resto. La revisión confirma, por otra parte, la existencia de dos mecanismos que operan para explicar estos impactos: por una parte, las mayores dificultades de los progenitores para invertir en servicios y productos que contribuyan al desarrollo de sus hijos/as y para garantizarles unas condiciones de vida adecuadas; por otra, el impacto de la carencia de recursos sobre el estrés y el funcionamiento familiar y sobre las capacidades parentales.

En todo caso, es importante destacar que el impacto de la ausencia de medios económicos en la infancia no se refiere únicamente a las consecuencias de la pobreza en el largo plazo. Para Strelitz y Lister -editoras de un libro titulado, precisamente, Por qué el dinero importa (2008)-, la cuestión relevante no radica tanto en las oportunidades vitales futuras, o en el impacto de la pobreza infantil sobre la igualdad de oportunidades, como en el impacto que la experiencia cotidiana de la pobreza tiene sobre la calidad de vida de los niños y niñas pobres y sobre su derecho a un nivel de vida decente. En el marco 
del paradigma del Estado social inversor, la pobreza infantil se ve fundamentalmente como un atentado a la meritocracia y a la igualdad de oportunidades $y$, por tanto, como un fenómeno no solo injusto sino también ineficiente, y cuyas implicaciones se manifiestan sobre todo a largo plazo. Para estas autoras, sin embargo, la cuestión crucial radica en el efecto que la pobreza tiene en la salud, la vivienda, la educación y el bienestar de las familias, es decir, en el impacto que la insuficiencia permanente de recursos tiene durante la infancia.

Más allá del impacto de la pobreza sobre y durante la infancia, ¿cuál es el que tienen las prestaciones familiares en cuanto a la prevención y la reducción de la pobreza infantil? En lo que se refiere al impacto de las prestaciones económicas familiares sobre el bienestar infantil y, específicamente, sobre la prevención de la pobreza infantil, podemos encontrar dos grandes tipos de aproximaciones o enfoques. La primera tiene un enfoque macroeconómico y la segunda un enfoque microeconómico, como veremos a continuación.

\section{a. La reducción de la pobreza infantil en perspectiva agregada}

Numerosos trabajos analizan esta cuestión desde una perspectiva agregada y relacionan los niveles totales de gasto y de cobertura de las prestaciones infantiles con las tasas generales de pobreza infantil en diferentes países. Desde ese punto, la conclusión parece clara: hay una amplia evidencia que apunta a que un apoyo público generoso a las familias con hijos/as está significativamente correlacionado con menores tasas de pobreza en los países en los que esas políticas se han desarrollado (Bárcena-Martín, Blanco-Arana y Pérez-Moreno, 2015; Engster, 2012). Como señalan Marí-Klose et al. (2019), existe una clara relación entre la inversión pública en políticas dirigidas a infancia y familia y la tasa de pobreza infantil y se observa que a mayor proporción de gasto del PIB en políticas orientadas a la familia e infancia, menor es la tasa de riesgo de pobreza infantil. En ese marco, señalan estos autores, la prestación por hijo a cargo es la política que en la mayoría de los países europeos tiene mayor capacidad para reducir la pobreza infantil.

En esa línea, Bárcena-Martín et al. (2015) demuestran que si se distingue el impacto correspondiente a las características sociodemográficas de la infancia y el correspondiente a las características de las políticas públicas destinadas a las familias con hijos/as en las tasas generales de pobreza infantil de cada país, se observa que las tasas de pobreza infantil son significativamente más bajas en aquellos países con prestaciones infantiles más generosas y más eficientes. Los paquetes de prestaciones económicas orientados a las familias con hijos/as, concluyen estos autores, parecen explicar en gran medida más allá del funcionamiento del mercado de trabajo o de las características particulares de las familias con hijos/as- las tasas generales de pobreza infantil de cada país, lo que, cabe añadir, convierte la cuestión de la pobreza infantil, en gran medida, en una opción política y social.

En un sentido parecido, Föster y Verbist (2014) demuestran tras comparar la situación en veintitrés países de Europa que las transferencias monetarias a los niños pequeños reducen los niveles generales de desigualdad y de pobreza. La magnitud del efecto depende de la cuantía de las prestaciones, así como de las características del sistema (por ejemplo, si se trata de prestaciones universales o no, o de si varían en función de la edad de los hijos y su número) y de la posición de las familias con hijos pequeños en la distribución general de ingresos. En todo caso, a juicio de estos autores, la aportación de las prestaciones infantiles a la reducción de la desigualdad es relativamente pequeña y, allá donde son más generosas, por cada punto del PIB dedicado a estas prestaciones se alcanza una reducción de la desigualdad cercana al 0,1\%.

En la misma línea, Gornick y Nell (2017) señalan que las prestaciones familiares -incluyendo en este caso los permisos de paternidad y maternidad- reducen la pobreza infantil en los países ricos de la OCDE en un $25 \%$, pasando del $24 \%$ al $18 \%$. La reducción total de la pobreza que se consigue mediante el conjunto de las transferencias sociales es de casi el $50 \%$ (del $24,1 \%$ al $13,8 \%$ ), con lo que las prestaciones familiares provocan en torno al $45 \%$ de la reducción de la pobreza infantil correspondiente al conjunto de las prestaciones sociales, siendo ese porcentaje mayor en los países del Este y menor en los escandinavos. Los datos de Gornick y Nell también dejan claro que, a mayor gasto en políticas familiares, mayor es la reducción de la pobreza infantil. Claramente, concluyen estos autores, las prestaciones familiares tienen un impacto destacado en la reducción de la pobreza infantil, si bien el resto de las prestaciones no ligadas a la infancia tienen un impacto similar.

Un reciente informe de la OCDE (Thévenon, Manfredi, Govind y Klauzner, 2018) apunta sin embargo a resultados diferentes y señala que las prestaciones que se vinculan en mayor medida con la reducción de la pobreza infantil son las prestaciones de vivienda, de asistencia social o garantía de ingresos y las pensiones, debido al elevado peso de las familias multigeneracionales en las familias pobres. El informe de la OCDE señala también, sin embargo, que la cuantía de las prestaciones familiares sí está relacionada con la reducción de la pobreza infantil, de forma que cada punto de incremento en la proporción que la prestación representa respecto al salario medio provoca una reducción de la pobreza infantil de un punto porcentual.

Un informe previo de la OCDE (Whiteford y Adema, 2007) había analizado en qué medida la reducción de la pobreza infantil puede ser alcanzada más fácilmente mediante una estrategia basada en la 
inserción laboral de sus padres y madres o por medio de una estrategia basada en las prestaciones económicas. En primera instancia, los autores del estudio indican que las prestaciones familiares juegan un papel importante en la reducción de la pobreza infantil en la mayor parte de los países de la OCDE, reduciendo un $40 \%$ las tasas de pobreza en el conjunto de los países analizados (con niveles que oscilan entre el $80 \%$ de Dinamarca y el 2,8\% de Portugal). Si todos los países fueran tan eficaces como los nórdicos a la hora de reducir la pobreza infantil, señala el informe, el número de niños/as pobres se reduciría a la mitad en todos los países de la OCDE. Inicialmente, por tanto, la estrategia prioritaria debería ser el refuerzo de estas prestaciones, incluso por delante del acceso de sus progenitores al mercado de trabajo, indica el informe.

La realidad es sin embargo más compleja, advierten los autores del estudio, en la medida en que, dada su situación de partida, algunos países deberían invertir cantidades muy superiores a las de los países nórdicos para alcanzar mediante transferencias económicas los mismos niveles de reducción de la pobreza que alcanzan los países del Norte de Europa. Por ello, los investigadores de la OCDE abogan por una estrategia que combine la mejora de las prestaciones familiares y la inserción laboral de sus progenitores. De hecho, concluyen, una política que incentive el acceso al empleo de estas personas es un pre-requisito para que las políticas predistributivas tengan mayor apoyo político y social.

Las prestaciones por hijo/a a cargo, en cualquier caso, no se aplican de forma aislada y forman parte de un régimen o modelo más amplio de prestaciones familiares. Engster y Stensöta (2011) analizan el impacto de los tres regímenes o modelos actualmente existentes en relación con la definición de las políticas familiares y demuestran que el modelo de doble perceptor de ingresos (dual earner model), muy basado en los servicios de atención infantil y los permisos de paternidad y maternidad, con prestaciones familiares de nivel medio o bajo, se relaciona con menores tasas de pobreza infantil, así como con una tasa de mortalidad infantil más baja y mejores índices de rendimiento académico. Desde ese punto de vista, las medidas de apoyo a la conciliación jugarían un papel más importante que las prestaciones por hijo/a a cargo a la hora de mejorar las condiciones de vida de la infancia.

Junto con las comparaciones internacionales, las comparaciones regionales ofrecen también datos de interés a este respecto. Un trabajo realizado por Cantó et al. en 2012 señala, con datos relativos al conjunto de las comunidades autónomas españolas en el año 2008, que las prestaciones infantiles de la Administración central (deducciones fiscales, prestación por hijo/a a cargo y cheque bebé, vigente en aquella época) reducen la pobreza infantil un $4 \%$, mientras que las políticas autonómicas lo hacen, en el mejor de los casos, un $1 \%$. En el caso de los niños/ as recién nacidos, dado el diseño de la mayoría de las prestaciones, la reducción es mayor y llega hasta el $11 \%$ en Extremadura. El estudio cifra en un $2 \%$ la reducción de la pobreza entre los niños/as recién nacidos en Euskadi, si bien, al no tenerse en cuenta las deducciones fiscales de los territorios forales (y sí en cambio las deducciones fiscales de otros territorios), los resultados no son comparables. De hecho, como explican Marí-Klose et al. (2019), el impacto de las prestaciones familiares en la reducción de la pobreza en España es muy reducido, debido a su escaso alcance, de tal forma que la pobreza de las familias con hijos/as se reducen en mayor medida mediante otras políticas, como las pensiones, que mediante estas prestaciones.

No es por tanto de extrañar el elevado impacto que una prestación por hijo/a a cargo -incluso de carácter universal- tendría de cara a la reducción de la pobreza infantil en España. En ese sentido, Ayala et al. (2020) han puesto de manifiesto el impacto que la puesta en marcha de una prestación universal podría tener a la hora de reducir las elevadas tasas de pobreza infantil en España. De acuerdo a sus trabajos, una prestación universal de ese tipo tendría un gran potencial para reducir la tasa de pobreza: un $18 \%$ la infantil y un $7 \%$ la adulta. En 2014 esto hubiera supuesto que la tasa de pobreza infantil española se redujese cinco puntos porcentuales y llegase a su nivel más bajo desde el 2004 y, en términos absolutos, que más de 450.000 niños y 550.000 adultos hubieran salido de la pobreza. Además, la prestación reduciría significativamente la tasa de pobreza de los hogares monoparentales y de las familias numerosas, y limitaría la desigualdad de rentas entre menores, rebajando en diez puntos porcentuales la distancia entre la renta disponible de los que tienen renta más alta y los que la tienen más baja ${ }^{19}$.

\section{b. El impacto de las prestaciones familiares en las condiciones de vida de la infancia}

El segundo enfoque utilizado en la literatura sobre prestaciones familiares y pobreza infantil se orienta a la medición del impacto que determinadas prestaciones han tenido en las tasas de pobreza y en las condiciones de vida de las familias beneficiarias en los países en los que estas medidas se han desarrollado.

Buena parte de la literatura al respecto proviene de las evaluaciones del modelo estadounidense de deducciones fiscales reembolsables, cuya capacidad para la reducción de la pobreza infantil parece suficientemente acreditada. De acuerdo a una revisión del impacto de las deducciones fiscales reembolsables sobre la reducción de la pobreza realizada recientemente por el SIIS Servicio de Información e Investigación Social (Zalakain, 2019), el impacto del Earned Income Tax Credit (EITC) norteamericano en la reducción de las tasas de

${ }^{19}$ No se han realizado simulaciones de este tipo para Euskadi. 
pobreza infantil y en la mejora de la situación de los niños/as de los hogares que perciben esta deducción parece fuera de toda duda.

En ese sentido, las evaluaciones del EITC en lo que se refiere a la reducción de la pobreza infantil ponen de manifiesto que esta desgravación reduce la pobreza en la infancia en torno a un $25 \%$ (Nichols y Rothstein, 2015). En una de las revisiones más amplias y recientes realizadas en relación con el EITC, estos autores señalan que millones de niños/a salen de la pobreza en Estados Unidos gracias a esta prestación y que su impacto positivo en términos de salud y educación tiene implicaciones significativas en lo que se refiere a la prevención de la transmisión intergeneracional de la pobreza. En el caso británico, Gregg et al. (2012) apuntan a un cierto éxito del sistema de deducciones fiscales en lo que se refiere a la reducción de las tasas de pobreza, con una relación clara entre el incremento en el gasto destinado a estas prestaciones $-\mathrm{y}$ al conjunto de las prestaciones familiares- $\mathrm{y}$ la reducción de las tasas de pobreza, especialmente entre la población infantil.

Especialmente en el entorno estadounidense, se ha identificado también un muy notable impacto del EITC sobre la salud, la alimentación o el rendimiento escolar de la población infantil. Un estudio reciente (Averett y Wang, 2016) pone de manifiesto el carácter multidimensional de los impactos del EITC sobre el bienestar infantil en la medida en que parece acreditado su efecto positivo en lo que se refiere a la salud, la calidad del entorno doméstico o las habilidades no cognitivas de los niños/as que residen en las familias que perciben la prestación, probablemente a través de la mejora de los ingresos familiares, los niveles inclusión laboral maternos y la mejora de su estado de salud física y mental. En una línea similar, Milligan y Stabile (2011) señalan que la extensión de las prestaciones infantiles en Canadá provocó efectos significativamente positivos en los resultados académicos de los niños/as beneficiarios, la salud de las madres y la salud mental de los niños/as. Los datos de este estudio señalan también que las mejoras educativas y de salud física afectan en mayor medida a los chicos, mientras que los beneficios relacionados con la salud mental afectan especialmente a las chicas.

Existe también una evidencia creciente en relación con el impacto del EITC en la salud de las mujeres que lo perciben y de sus hijos/as. Así, de acuerdo a Hoynes et al. (2012), los hijos/as de las mujeres que se beneficiaron en mayor medida de la expansión del EITC registraron mejoras significativamente mayores en diversos indicadores de salud infantil (bajo peso al nacer, nacimientos prematuros, etc.). Además, las madres que en mayor medida se beneficiaron del EITC recibieron una mayor atención prenatal y mantuvieron conductas, en relación por ejemplo el consumo de tabaco y alcohol, más saludables que el grupo de control. Del mismo modo, Evans y Garthwaite (2014) demostraron que la expansión del EITC tuvo como consecuencia una mejora en el estado de salud física y mental de mujeres a cargo de familias numerosas. En sentido parecido, Hoynes, Miller y Simon (2015) demostraron que un incremento de mil dólares en la percepción de la prestación se asocia con un reducción de entre el 1,6\% y el 2,9\% en las tasas de bajo peso al nacer, con reducciones aún más elevadas entre los hijos/as de madres de origen afroamericano.

Por otro lado, también parece estar demostrado el impacto de estas prestaciones sobre el rendimiento educativo de los niños/as que las reciben y puede decirse que existen conclusiones robustas en la literatura sobre este positivo impacto, con consecuencias significativas a largo plazo sobre diversos indicadores de bienestar en la edad adulta (Nichols y Rothstein, 2015). Dahl y Lochner (2009), a partir de una muestra de más de cinco mil niños/as, hallaron que un incremento de mil dólares en la prestación recibida por cada familia incrementaba un $6 \%$ los resultados en matemáticas y lectura, produciéndose las mejoras más importantes en los grupos menos favorecidos y en los niños/as de menor edad. Se trata, señalan los autores, de un efecto modesto aunque esperanzador. En el mismo sentido, a partir de una revisión de los estudios realizados en este ámbito, Duncan et al. (2011) han estimado que por cada tres mil euros adicionales de ingresos recibidos por la familia durante los primeros años del ciclo educativo, la mejora en el rendimiento escolar equivale a dos meses adicionales de escolarización.

Además de incidir en los resultados académicos, la percepción del EITC también parece afectar a la continuidad de los estudios. En ese sentido, se ha demostrado que un incremento en la cuantía máxima del EITC se asocia con incrementos en los niveles de escolarización a la edad de 19 años (Maxfield, 2013). En el mismo sentido, se ha demostrado que un incremento de la cuantía percibida de cien euros se asocia con un incremento de la matriculación en el último curso de educación secundaria de 0,3 puntos porcentuales (Manoli y Turner, 2018). Otros estudios han demostrado que por cada mil dólares percibidos vía EITC, la posibilidad de finalizar la educación secundaria se incrementa un 1,3\%, la de finalizar la universidad, un $4,2 \%$, la de acceder a un empleo en la época adulta, un $1 \%$ y los ingresos, un 2,2\% (Bastian y Michelmore, 2018).

El impacto positivo de este programa se asocia también con mejoras en el desarrollo infantil, cuando se analiza mediante técnicas longitudinales. Según Hamad y Rehkopf (2016), la percepción de la prestación se relaciona con una reducción en la prevalencia de trastornos conductuales en la población juvenil, con una reducción de entre el $2 \%$ y el $5 \%$ por cada incremento de mil dólares en las cantidades percibidas. Los autores señalan que estas mejoras pueden estar relacionadas con la mejora en el estado de salud física y mental de las madres puesta de manifiesto por otros estudios y que se mantienen, al menos en parte, en el medio y largo plazo. 
En definitiva, como señalan Bitler et al. (2018), la creciente evidencia de que "el dinero importa" pone de manifiesto que es posible mejorar las oportunidades de los niños y niñas en situación de pobreza incrementando la cobertura y la cuantía de las prestaciones familiares. Se trata además de una inversión económicamente sensata, afirman estos autores, si se tienen en cuenta los beneficios que la mejora de la situación económica de estos niños/as tendrá a medio y largo plazo en términos de empleo, salud o prevención de las conductas disfuncionales, y la posibilidad que las prestaciones en efectivo dan a las familias para acceder a los bienes y servicios que realmente necesitan. De acuerdo a los autores, el impacto de las prestaciones de apoyo a las familias se deriva tanto de la reducción del estrés parental asociado a la pobreza como de la posibilidad de invertir mayores recursos en el bienestar de sus hijo/as y en su educación ${ }^{20}$.

\subsection{Impacto sobre la fecundidad}

Un segundo ámbito de análisis en relación con el impacto de las políticas familiares -y, más concretamente, de las prestaciones por hijo/a a cargo- se refiere a sus efectos en cuanto a la fecundidad. Si bien se trata de una cuestión compleja, que depende en gran medida de otras políticas y determinantes sociales, la literatura revisada parece poner de manifiesto que existe una relación positiva, aunque pequeña, entre el desarrollo de estas prestaciones y el incremento de las tasas de fecundidad.

Los estudios y revisiones clásicos realizados fundamentalmente por Thévenon y Gauthier en la primera década de este siglo (Gauthier, 2007; Luci y Thevenon, 2011; Thévenon y Gauthier, 2011; Thévenon y Luci, 2012) ponen de manifiesto que las prestaciones económicas familiares tienen un impacto significativo sobre la fecundidad, si bien este impacto no es siempre fácil de observary puede variar en función del resto de las políticas familiares adoptadas - entendidas como un paquete global-y en función de los indicadores o patrones de fecundidad que quieran analizarse (paso del primer hijo/a al segundo/a, adelanto de la edad de procreación, incremento de la fecundidad de determinados perfiles de mujeres, etc.). En ese contexto, las principales cuestiones objeto de análisis se refieren al tipo de mujeres o parejas sobre las que este tipo de políticas tienen mayor impacto,

${ }^{20}$ Diferentes estudios han analizado el uso que las familias dan al dinero obtenido a través de estas prestaciones. Un análisis realizado por Jones et al. (Jones, Milligan y Stabile, 2015) muestra que los familias de menores recursos destinan el dinero obtenido mediante estas ayudas a financiar gastos educativos, así como otros bienes y servicios (comida, vivienda, transporte, etc.) que mejoran las condiciones de vida de la familia. La investigación añade que la percepción de estas ayudas contribuye a la reorganización del presupuesto familiar y a la reducción de los gastos en tabaco, alcohol u hostelería. Estos datos, afirman los autores, coinciden con otras investigaciones que apuntan a que la seguridad económica que las prestaciones ofrecen se traduce en una reducción de determinadas conductas de riesgo. a las variables sobre las que impacta -básicamente, cuándo tener hijos o cuántos hijos tener-y las características de las prestaciones que en mayor medida se relacionan con esos impactos.

En ese sentido, Gauthier (2007) señala que existe una cierta evidencia del impacto de las políticas familiares sobre la fecundidad, si bien este impacto tiende a ser pequeño y depende del tipo de datos utilizados y de las políticas analizadas. En lo que se refiere a las prestaciones económicas, cuando se analizan con datos macro, se observa una relación positiva entre la cuantía y el gasto en este tipo de políticas y las tasas de fecundidad: las prestaciones infantiles y las deducciones fiscales por hijo/a, señala Gauthier, parecen tener un impacto positivo en los índices agregados de fertilidad, si bien este impacto tiende a ser pequeño. Por otra parte, el impacto de estas prestaciones parece concentrarse más en un adelanto de los nacimientos que en el número de nacimientos propiamente dichos. Los estudios con datos micro ofrecen conclusiones aún menos categóricas, señala esta autora, aunque apuntan en la misma dirección: un impacto significativo, aunque pequeño.

En esa misma línea, Thévenon y Gauthier (2011) señalan que las prestaciones familiares tienen un innegable impacto en el timing de los nacimientos, si bien su impacto sobre la fecundidad del conjunto de una cohorte es más incierto. Para estos autores, la dificultad de identificar un impacto más consistente puede deberse en parte al hecho de que estos impactos solo se materializan a largo plazo y/o al hecho de que las familias destinan las prestaciones que reciben a mejorar la calidad de vida de los hijos/as que tienen, sin dar el paso a tener más descendencia. Ese efecto puede deberse a su vez, añaden, a las escasas cuantías que en general tienen estas prestaciones, lo que permite pensar que solo tienen efecto a partir de un cierto umbral. La generosidad de estas prestaciones se plantea en ese caso como crucial a la hora de marcar un cierto impacto en términos de natalidad.

Una revisión algo más reciente (Mathieu, 2013) confirma las conclusiones anteriores -las prestaciones familiares tienen un impacto positivo aunque reducido sobre la fecundidad-y aporta datos de interés acerca del impacto de las distintas políticas familiares sobre dos de las principales variables relacionadas con la fecundidad: el adelanto de la procreación y el incremento del número de hijos/as. Para la autora, las prestaciones periódicas (ya sea en forma de ayuda directa o de deducción fiscal) tienen un cierto efecto sobre el número de hijos ("efecto cuánto"), mientras que las ayudas o primas por nacimiento tienen impacto sobre el momento de tener descendencia ("efecto cuándo"). Para la autora, en cualquier caso, el concepto que más claramente se vincula a una mayor fecundidad es la "desmaternalización”, que define como el margen de libertad de las mujeres frente a la obligación de prestar cuidados. 
Los estudios desarrollados con posterioridad a estas revisiones apuntan a resultados parecidos. En el caso alemán, Riphanan y Wiync (2017) detectaron un impacto positivo de la mejora de las prestaciones familiares únicamente en familias de ingresos altos y en lo que se refiere al paso del primer/a al segundo/a hijo/a, lo que podría apuntar a un mayor efecto de estas prestaciones a medida que crece el tamaño familiar debido a las economías de escala que se generan. Otros resultados, también para Alemania (Rainer et al., 2014), indican un resultado parecido, pero de signo contrario: la fecundidad solo crece en las parejas con al menos un miembro con bajo nivel de estudios.

En una línea muy similar, Laroque y Salanie identificaron también un impacto significativo, si bien de pequeña magnitud, de los incentivos financieros dirigidos a las familias con hijos/as en Francia mediante deducciones fiscales y ayudas directas (Laroque y Salanié, 2008). De acuerdo a sus datos, un incremento de 150 euros mensuales en la prestación incondicional por hijos/a a cargo, con un coste equivalente al $0,3 \%$ del PIB, provocaría un incremento de la tasa de natalidad de la muestra analizada del 3,3 puntos porcentuales, con un incremento especialmente marcado en el caso de los terceros/hijos.

Los resultados de los estudios realizados en relación con las políticas familiares en España apuntan sin embargo a resultados más categóricos. En una serie de estudios sobre el impacto del cheque bebé introducido en España en 2004 sobre las concepciones y los abortos, González y Trommelová (2020) hallan que la introducción del cheque bebé incrementó un $3 \%$ las tasas de natalidad, debido tanto al incremento de las concepciones como a la reducción de los abortos. De acuerdo a los datos de estas autoras, la medida provocó en torno a 70.000 nacimientos adicionales, que equivalen a dos meses adicionales de nacimientos en un periodo de tres años.

El anuncio del establecimiento de esta prestación provocó un incremento del $4 \%$ en las tasas de natalidad debido a una notable reducción de las interrupciones de los embarazos, mientras que su cancelación trajo consigo una reducción del $6 \%$ en los nacimientos. Los datos de este estudio ponen de manifiesto, además, que mientras los efectos positivos (incremento de los nacimientos o reducción de los abortos) relacionados con el anuncio y puesta en marcha de la prestación se asocian a las mujeres de cualificación media o alta, los efectos negativos derivados de su supresión se vinculan a las mujeres de menor cualificación y/o menos vinculadas al mercado de trabajo. Los datos del estudio también sugieren que esta prestación afectó tanto al "cuándo" de los nacimientos, adelantándolos cuando se puso en marcha la prestación, como al "cuánto", incrementando el número de hijos/as que en circunstancias normales algunas mujeres hubieran tenido.
Más allá de la fecundidad, el cheque bebé español también parece haber contribuido a la estabilidad familiar, al menos a corto plazo. En ese sentido, un estudio sobre los efectos de esta prestación (González, 2011) indica que tuvo efectos positivos en términos de estabilidad familiar: las madres beneficiarias tenían un año después entre un $2 \%$ y un $5 \%$ menos de probabilidades de haberse separado al año del nacimiento, aunque no a los dos años, lo que quizá se relacione, señala la autora, con el carácter de pago único de la prestación.

Azmat y González analizaron también el impacto de otro de los grandes cambios en las políticas familiares españolas -la introducción en 2003 de un impuesto negativo para las mujeres trabajadoras con hijos de cero a tres años y el incremento de las deducciones para el conjunto de los contribuyentes mediante el mínimo vital- desde el punto de vista de la fertilidad, con resultados también positivos (Azmat y González, 2010). De acuerdo a sus datos, la combinación de ambas medidas provocó un incremento de la fecundidad de casi el $5 \%$.

Estos positivos resultados son semejantes a los identificados en un estudio previo para el caso británico a partir de los primeros incrementos de las prestaciones infantiles impulsadas por los gobiernos laboristas (Brewer, Ratcliffe y Smith, 2008). De acuerdo a este análisis, se produjo tras el desarrollo de estas políticas un incremento del $15 \%$ en las tasas de fecundidad de las mujeres directamente afectadas por las reformas (básicamente, mujeres de baja renta y/o niveles bajos de cualificación), debido en parte una reducción en el número de interrupciones del embarazo.

También en el caso de Canadá se identificaron efectos positivos del incremento de las prestaciones familiares sobre la fecundidad, de magnitud incluso mayor. De acuerdo a Milligan (2002), el incremento en las deducciones fiscales realizadas en el país provocó un incremento de la fecundidad de los grupos que podían acceder a la cuantía máxima de la prestación de un $25 \%$. El estudio señala además que, por cada mil dólares de incremento de la prestación, la probabilidad de tener un hijos/a se incrementa en un $16,9 \%$.

El caso de Australia ha sido objeto también de numerosas investigaciones. Los datos de una de las más recientes (Sinclair, Boymal y de Silva, 2015) confirman el impacto de la prestación universal por nacimiento establecida en aquel país en el año 2004. De acuerdo a sus datos, la introducción de aquella prestación no solo contribuyó a adelantar los nacimientos - una tendencia que en cualquier caso ya se estaba dando anteriormente en aquel país en plena fase de expansión económica-, sino también a incrementar las tasas globales de fertilidad. Otros estudios sobre la reforma australiana identificaron impactos en esa misma dirección, aunque de pequeña magnitud (Drago, Sawyer, Shreffler, Warren y Wooden, 2011; Parr y Guest, 2011). 
Algunos estudios realizados en relación con el caso italiano apuntan también a un incremento de la fertilidad como consecuencia de la aplicación del cheque bebé, especialmente en lo que se refiere a las mujeres de menor cualificación que ya tenían al menos un hijo/a (Boccuzzo, Caltabiano, Zuanna y Loghi, 2008).

Cabe citar, por último, otro reciente estudio que analiza las pautas de fecundidad de veinte países europeos entre 1960 y 2010 (Sánchez-Barricarte, 2017). Los resultados son de gran interés y apuntan a que el incremento en las prestaciones familiares se relaciona de forma estadísticamente significativa con un incremento de la fecundidad, mientras que el aumento del gasto en pensiones también tiene una relación estadísticamente significativa con la fecundidad, aunque de signo negativo. Estos datos probablemente indican, señala el autor, que lo que realmente disuade a las parejas de tener hijos/ as no es tanto el Estado del Bienestar como su desequilibrio y su orientación hacia el cuidado de las personas mayores en detrimento del apoyo a las familias jóvenes para afrontar los gastos de la crianza.

El incremento de la fecundidad puede, sin embargo, tener consecuencias inesperadas en términos de capital humano o desigualdad. Un reciente estudio basado en técnicas de modelización estadística (Petit, 2019) pone de manifiesto el elevado impacto de las deducciones fiscales estadounidenses en términos de fecundidad, con un incremento de hasta el $16 \%$, que se traduce en un aumento del número de hijos/as por hogar de 2,1 a 2,3. Ese incremento es, además, particularmente elevado entre las mujeres con niveles de cualificación más bajos (19\%, frente al $9 \%$ de las mujeres de cualificación más elevada). Los modelos utilizados prevén sin embargo que este incremento de la fecundidad se relacione con una menor inversión en capital humano, que resulta aún menor entre las familias de menor renta, lo que trae consigo un incremento de la desigualdad. Frente a este riesgo, los autores proponen sustituir las prestaciones directas por subsidios directos a la inversión en capital humano que, siempre según los modelos estadísticos aplicados, incrementan en la misma medida la fecundidad sin reducir la inversión en capital humano ni incrementar la desigualdad y la reproducción intergeneracional de la desventaja educativa.

\subsection{Impacto sobre el empleo}

Junto con los efectos de estas prestaciones sobre la pobreza y el bienestar infantil y sobre la fecundidad, también se ha analizado con gran detalle su impacto sobre la participación laboral, especialmente de las mujeres. Las dificultades para el análisis son similares a las anteriores - no siempre se distinguen suficientemente las prestaciones familiares por hijo/a a cargo de otras prestaciones como las destinadas a la conciliación y a la atención infantil- y también en este caso los impactos pueden hacer referencia tanto al margen intensivo (cuántas horas trabajan o dejan de trabajar las personas que reciben estas prestaciones), como al margen extensivo (cuántas personas dejan de trabajar, 0 se incorporan a un empleo, por el hecho de recibir estas prestaciones). A diferencia de lo que ocurría en el caso de la fecundidad, los resultados de las evaluaciones analizadas son poco coincidentes: en algunos países parece que estas prestaciones tienen un impacto significativo sobre la participación laboral de las mujeres -en el sentido de que reducen su actividad laboral a consecuencia de la percepción de estas ayudas-, mientras que en otros el efecto es positivo.

Los resultados, en cualquier caso, dependen en gran medida tanto del perfil de las mujeres - de su cualificación y estatus marital, fundamentalmentecomo del tipo de prestación analizada (especialmente su condicionalidad respecto al empleo) o del entorno socioeconómico en el que se implantan. Lo que la literatura sí parece demostrar es el mayor impacto de estas medidas sobre las mujeres $y$, particularmente, sobre las mujeres de renta y/o cualificación más baja, cuya oferta de trabajo es más elástica y está en mayor medida condicionada por variables externas.

Por una parte, un buen número de los trabajos analizados destacan el positivo efecto de este tipo de prestaciones, en términos de acceso al empleo, en los países con niveles reducidos de empleo femenino. En el caso de España, por ejemplo, Hernández Alemán et al. (2017) señalan que la introducción del cheque bebé en 2007 tuvo un efecto positivo en la oferta de trabajo femenino, al tiempo que redujo los costes que suponen un nuevo hijo/a, con un incremento medio de dos horas semanales de trabajo para las madres que se beneficiaron de esta ayuda. Este tipo de prestaciones universales, señalan las autoras, facilitan la participación de las madres en el mercado de trabajo y contribuyen a superar los obstáculos económicos que retrasan o impiden la maternidad.

Trabajos similares han encontrado, sin embargo, efectos contrarios para esa misma reforma. Según González (2013), las madres perceptoras de la prestación tenían al año siguiente entre un $4 \%$ y un $6 \%$ menos de posibilidades de seguir trabajando que las mujeres sin acceso a esta prestación. Analizando datos de la Seguridad Social, la autora observa que la percepción de la prestación redujo el acceso al empleo de estas mujeres entre una y dos semanas, por término medio, con una reducción de los ingresos salariales de setecientos euros. Para la autora, las madres habrían optado por comprar tiempo mediante la prestación, con la cual habrían financiado una semana adicional de permiso laboral.

Otros trabajos, también centrados en España, han analizado el impacto específico de las prestaciones familiares vinculadas a la participación laboral, como 
el impuesto negativo a las madres trabajadoras con hijos/as de cero a tres años introducida en España en 2003. Uno de los estudios (Azmat y González, 2010) que analizan esta prestación desde el punto de vista de la participación laboral femenina indica que-además de incrementar, como antes se ha dicho, la fertilidad un $5 \%$ - esta reforma incremento la participación laboral de las mujeres un $2 \%$, con un impacto más pronunciado entre las mujeres con menor cualificación. La autora añade que el efecto incentivador del empleo es en cualquier caso mayor -cercano al $5 \%$ - si se tiene en cuenta que la deducción por hijo/a a cargo introducida cuatro años antes mediante el mínimo vital había reducido la participación laboral femenina un $3 \%$. Se trata para la autora de un impacto particularmente alto, a la luz de los resultados de otras políticas similares realizadas en otros países, lo que quizá se explica por tratarse de una cuantía de relativa importancia (cien euros mensuales) que puede destinarse al pago de servicios de atención infantil.

Más recientemente, Oliver y Spadaro (2017) han analizado esta misma prestación mediante técnicas de microsimulación, planteando diversos escenarios en relación con su diseño y su cuantía. De acuerdo a sus datos, un incremento en la edad de los hijos/as que dan derecho a esa prestación tendría como consecuencia un incremento de la participación laboral femenina, si bien el coste fiscal de la medida sería también elevado. Los resultados de estos dos estudios coinciden con los obtenidos por SánchezMangas y Sánchez-Marcos (2008), de acuerdo a cuyos datos la medida provocó un incremento de la actividad laboral de las mujeres beneficiarias de estas prestaciones del 1,7\%, con un impacto más marcado entre las mujeres con menor cualificación.

En otros países, sin embargo, también con tasas de participación laboral bajas, el impacto derivado de la introducción de este tipo de prestaciones parece haber sido negativo. En el caso de Polonia, por ejemplo, diversos estudios (Magda, Kietczewska y Brandt, 2018) han puesto de manifiesto que la introducción de una prestación familiar de carácter cuasi universal ha tenido como consecuencia una reducción de la participación laboral femenina de entre el $2 \%$ y el $3 \%$, especialmente entre mujeres con niveles de cualificación bajos que residen en zonas rurales. Otros estudios realizados en relación con esta misma reforma señalan, sin embargo, que si en su primera versión -focalizada en familias de escasos ingresos- esta prestación sí redujo la participación laboral femenina, su universalización eliminó ese efecto (Myck y Trzciński, 2019).

En el caso canadiense, los resultados tampoco parecen haber sido positivos. Uno de los estudios más recientes en relación con la introducción de una prestación universal en aquel país (Schirle, 2015) pone de manifiesto una reducción relativamente importante de la participación laboral femenina, especialmente entre las madres en pareja con menor cualificación, cuya oferta de empleo resulta más elástica, es decir, se adapta con más facilidad a factores contextuales, como una fuente adicional de ingresos. En este caso, la posibilidad de estar ocupada se reduce para las madres con pareja de cualificación media o baja un 2,4\% y un $1 \%$ en el caso de las madres con mayor cualificación. El impacto sobre los padres es, por el contrario, prácticamente nulo. Otro estudio similar, también para Canadá (Koebel y Schirle, 2015), confirma el impacto de estas prestaciones en términos de reducción de la participación laboral femenina, si bien en este caso el impacto negativo solo se refiere a las mujeres con pareja, mientras que en el caso de las mujeres a cargo de familias monoparentales el impacto de esta prestación habría sido positivo. Para Schirle, autora de ambos estudios, los resultados demuestran que en lugar de comprar bienes y servicios para sus hijos/as gracias a estas prestaciones, lo que estas madres estarían comprando es tiempo para su cuidado o, en otros términos, una extensión de los permisos o excedencias disponibles para su cuidado. Esta compra de tiempo sería, a su juicio, más fácil y necesaria en el caso de las madres solas.

\subsection{Evidencia sobre el diseño de las prestaciones}

Para terminar este repaso de la literatura sobre el impacto de estas prestaciones, se analizan brevemente dos cuestiones relacionadas con el diseño de las prestaciones familiares: por una parte, el carácter universal o focalizado de estas prestaciones y, por otra, la opción entre las prestaciones directas y los beneficios fiscales, en forma de desgravación, exención o deducción fiscal.

\section{a. La fiscalización de las políticas familiares}

Como se ha visto en el análisis realizado en las páginas precedentes, una de las cuestiones esenciales en relación con el diseño de las prestaciones familiares se refiere a la opción entre las prestaciones directas o las herramientas fiscales (desgravaciones, exenciones, deducciones, etc.) y, dentro de estas, a su carácter reembolsable. Se trata de una cuestión relevante tanto por las consecuencias de utilizar estas herramientas en términos de redistribución y progresividad del sistema fiscal como por la creciente extensión de estos mecanismos fiscales de apoyo a las familias y, como se verá después, por su destacado peso tanto en el Estado español como en los territorios históricos vascos.

De acuerdo a Ferrarini, Nelson y Höög (2012: 7), "los Estados del Bienestar están siendo objeto de una sutil y en ocasiones inadvertida transformación: la fiscalización de las prestaciones sociales. Este cambio es especialmente notable en el ámbito de las políticas familiares, donde en los últimos años se han introducido una serie de créditos 0 deducciones fiscales infantiles que han modificado 
tanto el nivel como la composición de las políticas familiares". De acuerdo a estos autores, si en 1960 este tipo de herramientas se usaban en un solo país (Dinamarca), en 2005 se utilizan en trece. De hecho, es la expansión de este tipo de deducciones, a partir sobre todo de mediados de los años noventa, lo que explica el incremento en la cobertura de las prestaciones familiares que, en su ausencia, habrían ido reduciendo su capacidad de protección.

¿Qué impacto tiene esta fiscalización de las políticas familiares? Para Daly y Ferragina (2017), su extensión se vincula a un cierto retroceso de las ayudas directas. De hecho, si bien el valor del conjunto de las prestaciones familiares ha crecido en los países de la OCDE a lo largo de los últimos cincuenta años, pasando del $7,2 \%$ del salario medio al $12,1 \%$, en el caso de una familia biparental con dos hijos/as, el incremento se debe a la mayor suficiencia de las deducciones fiscales, que pasaron del 1,6 \% al 5,2 \% del salario medio, mientras que en el caso de las ayudas directas su capacidad se redujo del $5,7 \%$ al $4,8 \%$ entre 1990 y 2010.

De acuerdo a Ferrarini et al. (2012), no todos los países han optado sin embargo por este modelo de fiscalización. Mientras los países nórdicos han mantenido una trayectoria universalista mediante la utilización de prestaciones familiares universales, el recurso a las herramientas fiscales se ha utilizado fundamentalmente en Australia, Canadá, Alemania, Nueva Zelanda y Estados Unidos. El resto de los países analizados en su estudio -Austria, Bélgica, Francia, Italia, Japón, Países Bajos, Suiza y Reino Unido- habrían seguido una trayectoria mixta, en la que se combinan ambos tipos de enfoque ${ }^{21}$. Para estos autores, en cualquier caso, la utilización de estas herramientas fiscales comporta, en función de su diseño, ciertos riesgos.

A su juicio, el creciente recurso a los tax credits implica por una parte una erosión de las políticas universales, en la medida en que, en la mayor parte de los casos, estas deducciones están condicionadas al nivel de renta familiar, con lo que se contribuye a la generación de modelos más selectivos. También implican una reducción de las cuantías recibidas por las familias, dado que, en general, las cantidades de los créditos fiscales - salvo en Australia y Alemania- son más bajas que las correspondientes a las ayudas directas. Desde ese punto de vista, los autores señalan que los países que han seguido una trayectoria mixta tienden a ofrecer a las familias un nivel de protección mayor que aquellos que han apostado únicamente por las herramientas fiscales. A su juicio, por tanto, el recurso a los sistemas fiscales facilita el proceso de focalización de las prestaciones familiares señalado por Daly.

${ }^{21}$ De acuerdo al análisis realizado en las páginas anteriores, 17 de los 23 países analizados cuentan con herramientas fiscales de apoyo a las familias; de ellos, siete son deducciones reembolsables $y$ diez no reembolsables.
Dentro de este proceso de fiscalización coexisten, en cualquier caso, dos tipos de enfoques diferentes, que parten de lógicas en cierto modo contrapuestas. Las deducciones tradicionales - no reembolsablesse limitan a reducir la deuda tributaria de los contribuyentes, y se basan por tanto en una lógica de reducción de la presión fiscal para los contribuyentes de ingresos medios o bajos. Por definición, no benefician -o lo hacen en muy escasa medida- a los contribuyentes de muy bajos ingresos, con responsabilidades tributarias demasiado pequeñas para beneficiarse de una rebaja de impuestos, 0 quienes carecen de ingresos. Por el contrario, las deducciones reembolsables benefician a todas las personas potencialmente beneficiarias, ya que si el montante de la deducción es superior a la deuda tributaria, la diferencia se abona a las personas contribuyentes como una prestación neta (Zalakain, 2019).

Resulta, por tanto, del máximo interés analizar los efectos de las deducciones fiscales reembolsables frente a las deducciones convencionales. En ese sentido, un reciente artículo de Avram (2017) analiza el efecto redistributivo de las deducciones fiscales y las desgravaciones o reducciones de la base imponible desarrolladas en seis países de Europa. De acuerdo a su análisis, las desgravaciones o reducciones en la base son por lo general regresivas, mientras que las deducciones en la cuota son neutrales o moderadamente progresivas ${ }^{22}$. En todo caso, advierte la autora, el impacto de estas herramientas desde el punto de vista redistributivo es poco claro y difícil de prever, en la medida en que está estrechamente relacionado con el resto de las características del sistema impositivo (tipos, posibilidades de declaración conjunta e individual, bases exentas, etc.), lo que desaconseja su utilización como herramienta redistributiva.

Avram destaca sin embargo que la naturaleza reembolsable de algunas de estas deducciones supone un cambio radical en la capacidad redistributiva de estas deducciones. Para la autora, "ni las desgravaciones ni las deducciones son herramientas particularmente efectivas desde el punto de vista redistributivo. Sin embargo, hay una excepción: los créditos fiscales reembolsables dirigidos a hogares de bajos ingresos. Si bien la muestra utilizada en este análisis contiene muy pocos ejemplos de tales instrumentos para justificar una conclusión sólida, encontramos que los créditos fiscales reembolsables son fuertemente progresivos, independientemente del entorno en el que operen" (Avram, 2017: 284).

${ }^{22}$ El argumento de Avram coincide con el de Van Lancker y Van Mechelen (2015), que señalan que las deducciones fiscales convencionales contribuyen a la focalización de las políticas familiares aunque en sentido inverso al habitual, ya que se benefician de ellas principalmente las familias de renta media y alta. Este efecto, de acuerdo a estos autores, es particularmente evidente en países como España. 
Existe poca evidencia respecto a la fiscalización de las prestaciones familiares en el Estado español -y apenas ninguna en Euskadi- pese a la importancia que las herramientas tributarias tienen en ambos territorios. Cantó et al. (2012) ponen de manifiesto el elevado gasto medio del Gobierno central en estas prestaciones (en torno a setecientos euros por niño/a en 2008), frente a apenas doscientos en prestaciones directas (aún en el momento en el que estaba vigente el cheque bebé). En cuanto a su efectividad, Ayala y Cantó (2009) señalan que las reducciones impositivas provocan en general una pérdida de la capacidad redistributiva del Estado hacia las rentas más bajas, ya que estas no se benefician de las reducciones de la fiscalidad y se ven penalizadas por el recorte que, a medio o largo plazo, la menor capacidad económica pública provoca en los servicios y prestaciones públicas. En relación con la pobreza infantil, estos autores señalan que "las desgravaciones y deducciones fiscales encaminadas a apoyar a las familias trabajadoras con niños suelen tener efectos nulos o pequeños sobre los ingresos de los hogares con rentas muy bajas que, en general, no están obligados al pago de impuestos sobre la renta, por lo que es importante que las deducciones fiscales sean reembolsables como subsidios para los que no tributan. Si así fuera, estas políticas pueden tener efectos positivos en la reducción de la pobreza infantil" (Ayala y Cantó, 2009: 36).

Más recientemente, Marí-Klose et al. (2019) han analizado el sistema de prestaciones y deducciones orientadas a la familia y la infancia en España, destacando la escasa capacidad redistributiva tanto del sistema prestacional como del fiscal. En lo que se refiere a las herramientas fiscales, los autores señalan que este tipo de políticas fiscales no pueden llegar a tener un efecto excesivamente relevante en la reducción de la pobreza, ya que una parte importante de los hogares que se sitúan por debajo del umbral de la pobreza están exentos de tributar por IRPF. Dejando de lado el mínimo vital, los autores señalan que las deducciones por hijos/as -tanto del tramo estatal como del autonómicoapenas llegan al $14 \%$ de las familias con hijos/as que realizan la declaración de la renta, con una cuantía media cercana a los dos mil euros. Se trata además de un mecanismo regresivo, en la medida en que es en el quintil de renta inferior donde el porcentaje de beneficiarios de estas deducciones es menor, pese a que en tal quintil la proporción de familias con hijos/as sea mayor. Los datos muestran, según los autores, que las familias más empobrecidas son las que, en número, menos se benefician de las deducciones en conceptos de infancia. En cambio, la cuantía media global deducida (de los que han deducido algún concepto relacionado con la infancia) no varía mucho entre los distintos quintiles.

El spending review publicado en julio de 2020 por la Autoridad Independiente de Responsabilidad Fiscal (Airef) ofrece sin embargo conclusiones más positivas: el informe analiza el conjunto de los beneficios fiscales existentes en el marco del sistema tributario español y, dentro de ellas, las deducciones por maternidad, discapacidad y familia numerosa, que incluyen un componente de reembolsabilidad y se definen por la propia Agencia Tributaria como "impuestos negativos".

En lo que se refiere a las deducciones sociales, el informe de la Airef cuantifica su gasto en 1.718 millones de euros anuales, de los que el $44 \%$ corresponden a la deducción por maternidad, el $36 \%$ a la deducción por familia numerosa y el $20 \%$ a la deducción por persona con discapacidad a cargo. El informe señala que la deducción tiene un impacto positivo pequeño, pero significativo, tanto en lo que se refiere a la participación laboral de las mujeres con hijos/as menores de tres años como a la natalidad. En lo que se refiere al componente de reembolsabilidad de estas deducciones, indica que "al configurarse como un impuesto negativo, estas deducciones tienen una naturaleza progresiva que reduce la desigualdad" (Autoridad Independiente de Responsabilidad Fiscal, 2020: 144).

\section{b. El debate entre universalidad y focalización}

Una de las principales variables que definen las prestaciones por hijo/a a cargo radica en su universalidad, es decir, en el hecho de que el acceso a estas prestaciones esté o no determinado por el nivel de ingresos de las familias. Como se ha explicado anteriormente, 17 de los 23 países analizados en este estudio disponen de prestaciones universales o casi universales, de tal forma que la prestación puede ser percibida por todas las familias independientemente de su nivel de renta, aunque la cuantía sí pueda estar modulada en función de los ingresos.

El debate sobre los efectos de la universalidad de las políticas sociales y, específicamente, de las prestaciones económicas, ha estado dominado desde finales de los años noventa por el trabajo de Korpi y Palme (1998) en el que se defendía la mayor capacidad redistributiva de las políticas universales frente a las selectivas o focalizadas, orientadas a las personas con ingresos inferiores a un umbral determinado, debido fundamentalmente al mayor apoyo que cosechan entre las clases medias. La focalización, por el contrario, dificultaría la articulación de las coaliciones necesarias para garantizar el respaldo social y presupuestario a estas medidas, lo que a su vez comprometería su tamaño y efectividad. Veinte años después de la publicación del aquel artículo, algunos trabajos han venido a cuestionar aquellas conclusiones $\mathrm{y}$ han defendido que -debido, entre otros elementos, a la activación ${ }^{23}$ de muchas prestaciones-el apoyo público a las políticas focalizadas es hoy día mayor y no puede

${ }^{23}$ El paradigma de la activación se materializa en una mayor condicionalidad de las prestaciones y una mayor vinculación entre el derecho a la prestación económica y el derecho, o la obligación, a participar en actividades de inclusión social y laboral. 
decirse que reduzcan en menor medida la pobreza debido a su menor tamaño (Marx, Salanauskaite y Verbist, 2013). Otros análisis han puesto de manifiesto que si bien la reducción de la pobreza se relaciona con una mayor universalidad, las políticas universales no se asocian ya a mayores apoyos a favor de la redistribución (Brady y Bostic, 2015). Tampoco se encuentra ya una correlación, según estos estudios, entre universalidad y mayor gasto social, lo que invalidaría la tesis básica de Korpi y Palme.

En sentido parecido, una reciente revisión realizada por Gugushvili y Laenen (2019) cuestiona las conclusiones de Korpi y Palme y concluye que, si bien es cierto que un mayor gasto público se asocia a menores tasas de pobreza y desigualdad, un menor gasto público puede ser compensado con una mayor focalización en las familias de menores ingresos, aportando mayor efectividad. Estos autores refutan la teoría de las coaliciones de apoyo a la redistribución, que a su juicio está más basada en razonamientos teóricos que en datos empíricos.

Otros trabajos recientes defienden sin embargo que se mantiene en la actualidad la paradoja señalada por Korpi y Palme y que las prestaciones universales siguen teniendo, pese a su menor focalización, una mayor capacidad redistributiva. En ese sentido, Jaques y Noël (2018) han revisado recientemente la hipótesis anterior utilizando datos actualizados, operativizando de forma diferente los conceptos de universalidad y focalización, y diferenciando el efecto que en determinadas políticas pueden tener las características sociodemográficas de sus beneficiarios ${ }^{24}$. De acuerdo a sus datos, las políticas universales se relacionan con una mayor capacidad redistributiva, una mayor capacidad de reducción de la pobreza y menores niveles de desigualdad. La universalidad también se relaciona con un mayor gasto público y este, a su vez, con una mayor capacidad redistributiva. También se observa una relación clara entre universalidad de las prestaciones y mayor apoyo público a la redistribución. La universalidad se configura, de acuerdo a este análisis, como un significativo predictor del gasto público, los niveles de desigualdad, redistribución y reducción de la pobreza, incluso cuando se tienen en cuenta otras variables como el PIB per cápita, el desempleo o las tasas de dependencia.

En un sentido parecido, McKnight (2015), tras analizar los datos para Reino Unido, Italia, Suecia y Francia entre 1974 y 2010, rechaza la hipótesis de que una mayor focalización se relacione con una mayor capacidad redistributiva o de reducción de la pobreza, e indica que en los momentos en los que dentro de un país se ha optado por políticas

${ }^{24}$ Los autores parten de la idea de que una política universal puede tener efectos focalizados en función de quiénes sean en la práctica sus principales destinatarios: la gratuidad universal de las matrículas universitarias, por ejemplo, se focaliza en la práctica hacia las familias de renta media y alta, que son las que acceden con mayor frecuencia a la universidad. más focalizadas, la reducción de la desigualdad y de la incidencia de la pobreza ha resultado menor. Las tesis de Korpi y Palme se verían de esta forma confirmadas.

Más allá de estos debates generales, en el ámbito de las políticas familiares o de infancia parece claro que se ha dado en los últimos años un incremento de las políticas focalizadas en detrimento de los enfoques universales. En una reciente revisión de este tipo de políticas, Daly y Ferragina (2017) señalan efectivamente que en los últimos años se ha producido un retroceso en el alcance de las políticas universales, acompañado de un mayor recurso a las herramientas fiscales, que se analizan en el siguiente epígrafe.

En todo caso, los argumentos a favor de la universalidad de las prestaciones familiares son abundantes en la literatura revisada. De acuerdo a Bradshaw (2011), las prestaciones familiares universales fomentan la equidad horizontal -es decir, el objetivo de garantizar un nivel similar de ingresos a personas con responsabilidades familiares diferentes-, incrementan la fecundidad, reducen la pobreza -de acuerdo a este autor, casi tanto como las prestaciones focalizadas-y mejoran el bienestar infantil. Tienen menos problemas de no acceso o non take up que las prestaciones focalizadas, resultan más fáciles y baratas de gestionar, tienen mayor apoyo social y evitan las trampas de la pobreza asociadas a las prestaciones condicionadas a la participación laboral. Por el contrario, las prestaciones familiares focalizadas tienden a ser de reducida cuantía debido precisamente a su selectividad y a la falta de apoyo social, en la línea de lo defendido por Palme y Korpi, tienden a estar excesivamente focalizadas -dejando al margen no solo a las familias con recursos suficientes, sino a muchas con recursos insuficientes-, y presentan problemas de non take up y otros problemas administrativos, como los pagos indebidos. Todo ello, afirma, provoca que estas prestaciones tengan una menor capacidad de reducción de la pobreza infantil que las prestaciones universales. También Townsend abogó con claridad ya en los primeros años setenta a favor de la universalidad de las prestaciones infantiles, tanto en los países ricos como en los países en vías de desarrollo (Walker, Sinfield y Walker, 2011).

Desde una visión más orientada a los argumentos económicos, Atkinson (2011) ha defendido también la idoneidad del enfoque universalista frente a las aproximaciones focalizadas. A su juicio, la focalización de las prestaciones supone en la práctica el incremento del tipo de imposición marginal del impuesto sobre la renta, en la medida en que grava el incremento de ingresos propios de las familias en una cantidad muy superior a los tipos marginales que se aplican a la mayor parte de los contribuyentes. Frente a esa estrategia, Atkinson se muestra favorable a mantener la universalidad de las prestaciones familiares incrementando los tipos 
que se aplican a las rentas más altas y haciendo tributables esas prestaciones. Otra de las ventajas que se asocia a las prestaciones universales, a juicio de Atkinson, se refiere a que no presenta los problemas de non take up que se asocian a las prestaciones selectivas o focalizadas, que se derivan tanto de la complejidad del proceso de solicitud como del estigma que a menudo se le asocia.

En todo caso, la cuestión de la focalización puede plantearse desde dos perspectivas: la primera se centra en la focalización en las familias pobres, independientemente de la edad de sus miembros. La segunda se centra en la focalización en la población infantil, independientemente de su renta ${ }^{25}$. En ese sentido, un reciente artículo de Bárcena-Martin et al. (2018) defiende que, para la reducción de la pobreza infantil, las prestaciones universales focalizadas en la infancia -es decir, las prestaciones familiares universales (pro-child targeting) — resultan más efectiva que las prestaciones focalizadas en las personas pobres (pro-poor targeting). A partir de un análisis de la efectividad de los sistemas de impuestos y prestaciones de los países de la Unión Europea, estos autores ponen de manifiesto, por una parte, que las tasas de pobreza infantil de los diversos países se relacionan más con el diseño institucional del Estado del Bienestar que con las características sociodemográficas de la población infantil. Además, la investigación muestra que la reducción de la pobreza infantil se vincula más a la focalización sobre la infancia que a la focalización sobre la pobreza.

Más concretamente, la investigación revela que si bien la focalización en los pobres reduce las tasas de pobreza infantil, sobre todo si esa focalización viene acompañada de un gasto elevado, la focalización en las familias con hijos resulta aún más efectiva. Ambas formas de focalización son efectivas, concluyen los autores, si bien la focalización en la infancia resulta más efectiva que la focalización en las familias pobres. La razón de este efecto estriba la posición de las familias con hijos en la escala de ingresos, en la medida en que buena parte de las familias con hijos se concentran en los estratos de menor renta, aunque en esos estratos el número de familias sin hijos/as es también muy elevado.

De esta manera, las prestaciones focalizadas en el conjunto de la infancia resultarían más adecuadas tanto en términos de equidad vertical -en la medida en que reducen la pobreza infantil- como en términos de equidad horizontal, en la medida en que contribuyen a compensar los costes de la crianza de todas las familias con hijos/as y a equilibrar las condiciones de vida de las personas con y sin hijos/as. Efectivamente, las prestaciones por hijo/a a cargo pueden tener un objetivo de mejorar los niveles de equidad vertical (entre ricos y pobres), pero también

${ }^{25}$ Obviamente, una tercera vía consiste en focalizarse en las familias pobres con hijos/as. horizontal (entre personas con hijos y sin hijos, al objeto de compensar los gastos de la crianza).

Para analizar la compatibilidad o incompatibilidad entre ambos enfoques, Verbist y Van Lancker (2016) plantean una metodología para medir al mismo tiempo la equidad vertical y la equidad horizontal de diversos modelos de prestaciones infantiles, teniendo en cuenta, por una parte, cuánto reducen la pobreza y, por otra, qué porcentaje del coste de la crianza cubren, así como el carácter (selectivo o universal) y el tamaño (en términos de gasto público) del modelo. De acuerdo a este análisis, ambas dimensiones - equidad vertical y equidad horizontal- están estrechamente relacionadas: los países que compensan en mayor medida los costes de la crianza para el conjunto de las familias con hijos/as son los que en mayor medida reducen la intensidad de la pobreza de las familias con hijos/as. Debido, como también apuntaban Bárcena-Martín et al., a la distribución sociodemográfica de la población infantil, no hay dilema entre equidad vertical y equidad horizontal: aunque un país destine sus prestaciones infantiles al conjunto de las familias con hijos/as independientemente de su renta, la ubicación de las familias con hijos/as en la escala socioeconómica hace que esas prestaciones tengan, por defecto, un impacto relevante desde el punto de vista de la equidad vertical, es decir, desde el punto de vista de la reducción de la pobreza infantil.

En todo caso, los resultados de Verbist y Van Lancker ponen también de manifiesto -junto con la importancia de las características sociodemográficas de la infancia para explicar el impacto de las diversas orientaciones que se plantean-, la importancia del tamaño del sistema de prestaciones, es decir, de las cuantías de esas prestaciones y del gasto público resultante. En ese sentido, el debate entre focalización y universalidad no pude dejar de tener en cuenta la cuestión del tamaño. El análisis del sistema ruso de prestaciones familiares (Notten y Gassmann, 2008) pone de manifiesto que una prestación universal resultaría más efectiva que una prestación selectiva a la hora de la reducción de la pobreza infantil, debido fundamentalmente a la inclusión de muchas familias pobres con hijos/as que no acceden a la prestación debido a problemas administrativos y de gestión. En todo caso, señalan, solo con un incremento sustancial de la cuantía de las prestaciones puede alcanzarse una reducción sustancial de la pobreza infantil.

La cuestión del tamaño resulta particularmente importante en el marco del Estado español, en la medida en que las prestaciones por hijo/a cargo existentes son de muy escasa cuantía. En ese sentido, como explica Cantó (2018), para medir la capacidad redistributiva de cualquier sistema es necesario fijarse en dos elementos clave: la progresividad y la dimensión tanto de los impuestos directos como de las prestaciones monetarias para los más necesitados. Ambos son importantes y por separado no consiguen, en ninguna parte del mundo, 
que los efectos redistributivos de una política pública sean potentes ${ }^{26}$. En la práctica, los datos apuntan a que los países que han aumentado el efecto redistributivo de alguna de sus políticas lo han hecho porque han incrementado la dimensión de la política y no su progresividad.

Frente a la defensa de la universalidad de las prestaciones infantiles, otros autores han puesto de manifiesto las ventajas de una aproximación selectiva y, más concretamente, la necesidad de combinar ambos enfoques desde una perspectiva que cabe llamar universalismo focalizado, en la línea de los planteamientos defendidos por Skocpol en 1991 (Skocpol, 1991). En ese sentido, Van Lancker y Van Mechelen (2015) cuestionan los postulados de Korpi y Palme desde la perspectiva de las prestaciones familiares y señalan que la focalización en las familias pobres obtiene mejores resultados en términos de reducción de la intensidad de la pobreza. Si bien los sistemas universales siguen siendo los que destinan un mayor gasto público a estas políticas, lo que refuerza la idea del apoyo de las clases medias a las políticas universales, la cuantía de las prestaciones tiende a ser mayor en los modelos selectivos, lo que provoca una mayor capacidad de reducción de la pobreza. Sin embargo, algunos modelos selectivos resultan incapaces de reducir sustancialmente la pobreza, en parte debido a que - al basarse en desgravaciones y deducciones fiscales no reembolsables- se focalizan hacia las rentas medias y altas, y no hacia las bajas. Por ello, a juicio de estos autores, la estrategia más adecuada pasa por un universalismo focalizado (targeting within universalism) que combina niveles elevados de gasto público y prestaciones universales con prestaciones selectivas de elevada cuantía orientadas a las familias de menor renta.

En un sentido parecido, Bárcena-Martín et al. (2015) defienden que los países que aplican ese enfoque de universalismo focalizado obtienen resultados más positivos en cuanto a la reducción de la pobreza. De acuerdo a estos autores, los programas focalizados en los niños/as de renta baja que refuerzan estrategias generosas de transferencias universales son la mejor opción para el diseño de las prestaciones familiares desde el punto de vista de la reducción de la pobreza infantil. En la misma línea, aunque en relación con las familias monoparentales, Morissens (2018) señala que los países que combinan unas prestaciones universales generosas con prestaciones adicionales para las familias monoparentales son las que obtienen mejores resultados a la hora de reducir la pobreza

\footnotetext{
${ }^{26}$ Cantó ilustra el argumento con el siguiente ejemplo. Imaginemos una sociedad con dos individuos, uno rico y uno pobre, y en la que hay un impuesto progresivo. El primer individuo (rico) gana 10.000 euros y paga 500 de impuesto, un $5 \%$ de tipo medio efectivo sobre su renta bruta. El segundo, el pobre, gana 1.000 y paga 10 euros, solo un $1 \%$. Con este diseño el impuesto no consigue ser muy redistributivo porque, aunque es muy progresivo y el rico paga cinco veces más que el pobre por cada euro que gana, su peso sobre la renta bruta es realmente pequeño y ambos ciudadanos pagan poco en proporción a lo que ingresan.
}

infantil y ofrecer a estas familias unas condiciones decentes de vida.

Este debate apunta a la importancia de calibrar adecuadamente el grado de focalización y universalidad de cualquier sistema de prestaciones familiares. Es en ese marco donde adquiere sentido el recurso a los beneficios fiscales reembolsables. Efectivamente, tal y como señala la Fundación Foessa en su informe sobre la reorientación del sistema de garantía de ingresos en España, “las prestaciones familiares deben tender a tener un carácter lo más universal posible, y beneficiar al conjunto de las familias con hijos/a a cargo. Ello no impide reconocer la necesidad de prestar un apoyo económico específico, más intenso, a las familias con mayores necesidades. Pero no tiene sentido seguir manteniendo un sistema dual, en el que la mayor parte de las familias obtengan beneficios fiscales - no completamente universales-y que las familias más pobres accedan a un sistema selectivo e insuficiente" (Fernández, 2015: 90).

El informe de la Fundación Foessa añade que "dado que se está haciendo ya un esfuerzo económico importante (estimado en unos 4.500 millones de euros anuales) en políticas fiscales de apoyo a las familias con hijos/as, podría ser interesante avanzar en la vía de la integración de las prestaciones sociales y las políticas fiscales, tal y como han hecho muchos países de nuestro entorno. La vía más adecuada sería la extensión, con carácter gradual, de las actuales deducciones reembolsables a todas las familias con hijo/a a cargo. La potenciación de la vía fiscal nos parece especialmente interesante en la medida que abre a la protección social formatos ya consolidados de organización administrativa. Sin embargo, habrá que poner un especial esfuerzo en que, si se utilizan las herramientas fiscales, aquellas personas que no hacen habitualmente declaración de la renta por estar exentas, pueden quedar de nuevo al margen de estos beneficios" (Fernández, 2015: 90).

En un sentido parecido, Noguera (2019) plantea, entre otras opciones, la posibilidad de integrar las prestaciones familiares por hijo a cargo con la fiscalidad. Para Noguera, “convertir el mínimo por descendientes del IRPF en prestación por hijos a cargo tendría un efecto relativamente modesto sobre la renta disponible de los contribuyentes, pero visibilizaría ese gasto como prestación (ahora está oculto en el impuesto) y legitimaría políticamente su extensión a todas las familias con bajos ingresos y/o que no declaran por IRPF. No cabe descartar, asimismo, que señalizarlo como prestación directa ligada a los menores de edad tuviese efectos en la conducta de muchos padres a la hora de destinar dinero en mayor proporción a finalidades relacionadas con el bienestar de sus hijos. Además, y no menos importante, el efecto de dicha medida sería netamente progresivo, pues en la actualidad la 'prestación oculta' que reciben todos los contribuyentes del IRPF con hijos a cargo a través del mínimo por descendientes es más alta que 
la prestación por hijos de la Seguridad Social que reciben los hogares con más bajos ingresos, muchos de los cuales ni siquiera presentan la declaración por estar exentos de ello".

\section{Conclusiones}

La revisión de la literatura publicada en relación con el funcionamiento y el impacto de las prestaciones por hijo/a a cargo permite extraer varias conclusiones de interés: de forma resumida, puede decirse que hay evidencia suficiente para afirmar que las prestaciones familiares, infantiles o por hijo/a cargo reducen la pobreza infantil; mejoran la situación de los niños/as y de sus familias, incluso a medio y largo plazo, desde el punto de vista educativo y de salud; $y$ tienen un efecto positivo (aunque reducido) en el incremento de la fecundidad. Estas prestaciones parecen inducir también una reducción de la vinculación de las mujeres al mercado laboral, que podrían destinar estas prestaciones a comprar "tiempo" para el cuidado, alargando sus permisos laborales.

La revisión realizada permite afirmar también que se mantiene una positiva relación entre el carácter universal de estas prestaciones y su capacidad para la reducción de la pobreza, y que las prestaciones universales presentan, frente a las selectivas o focalizadas, más ventajas que inconvenientes. Los trabajos analizados apuntan en cualquier caso a la necesidad de avanzar hacia un universalismo focalizado (targeting within universalism). Efectivamente, las estrategias que han tenido más éxito para abordar la pobreza infantil han demostrado ser las sustentadas en políticas destinadas a mejorar el bienestar de todos los niños y niñas, teniendo especialmente en cuenta, al mismo tiempo a los niños, y a las niñas que se encuentran en situaciones particularmente vulnerables.

Impulsar un paquete amplio de políticas familiares de corte universal permitiría, por otro lado, reequilibrar - al menos en cierta medida- el sesgo que nuestro Estado del Bienestar tiene hacia las personas mayores, reconstruir el maltrecho contrato intergeneracional y, al mismo tiempo, sentar las bases para garantizar la sostenibilidad de ese Estado del Bienestar.

Efectivamente, la abundante literatura relacionada con la contabilidad intergeneracional que se ha ido produciendo en los últimos años - basada en la metodología de las Cuentas Nacionales de Transferencias- pone de manifiesto en qué medida los Estados del Bienestar están orientados hacia el gasto en las personas mayores. Para Solé et al. (2020: 4) "la redistribución intergeneracional es en todos los países claramente asimétrica en favor de las personas mayores, mientras que las necesidades de los niños/as son básicamente cubiertas por sus familias". De acuerdo a Abío et al. (2019: 130), "el sesgo hacia una mayor protección de las personas de más edad es una característica prácticamente universal de los Estados del Bienestar. Cabe preguntarse por qué los diferentes países, a medida que desarrollaban sus programas de gasto social han ido dando prioridad a aquellos dirigidos a la población mayor, dejando la financiación de los niños/as de manera casi exclusiva en la familia. Si uno de los objetivos del Estado del Bienestar es socializar (repartir entre toda la sociedad para reducir desigualdades) el gasto de mantener a los dependientes, es difícilmente justificable que solo deba ser así en el caso de los mayores, y no en el de los niños [...]. Como consecuencia de este sesgo de las políticas públicas, las familias asumen la mayor parte del coste monetario de los niños, al que hay que añadir el coste en términos de tiempo" que requiere la crianza de los hijos/as.

Los trabajos basados en las Cuentas Nacionales de Transferencias también ponen de manifiesto en qué medida la sostenibilidad del aumento del gasto social que requiere el envejecimiento depende, paradójicamente, de la inversión que se haga en medidas dirigidas a la inversión en capital humano -es decir, en políticas de infancia, de familia y educativas-, puesto que se ha demostrado que la mejora del capital educativo de las cohortes jóvenes tiene un impacto superior al resto de los cambios sociodemográficos en lo que se refiere a la sostenibilidad fiscal del Estado del Bienestar ${ }^{27}$.

En efecto, la capacidad de financiación del gasto social público depende tanto del crecimiento de la productividad y de la creación de riqueza como del propio incremento del gasto a financiar. El crecimiento económico, a su vez, depende de la actual capacidad de invertir en las políticas educativas, de juventud, de infancia, de natalidad y de apoyo a las familias: la mejor manera de garantizar la sostenibilidad de los cuidados de quienes serán dependientes dentro de 50 años es invertir ahora en su educación y en sus condiciones de vida, fomentar la movilidad social y evitar la reproducción intergeneracional de la pobreza.

${ }^{27}$ Para Hammer et al. (2019), aunque la importancia de la inversión en el capital educativo de las cohortes más jóvenes en el funcionamiento del contrato intergeneracional es esencial, no ha sido suficientemente tenida en cuenta a la hora de evaluar la sostenibilidad económica de los modelos de protección social desde el punto de vista intergeneracional. El contrato intergeneracional es, fundamentalmente, una cuestión de inversión a largo plazo, que debe resultar suficiente para obtener los resultados esperados en el futuro: las actuales generaciones adultas invierten en el capital humano de sus hijos/as y reciben en el futuro los retornos de esa inversión en forma de pensiones, cuidados de salud y servicios de atención a la dependencia. Así pues, una orientación excesivamente marcada del actual gasto social hacia las personas mayores compromete, paradójicamente, la posibilidad de financiar el gasto de las personas mayores del futuro, que son, también paradójicamente, las personas adultas que están financiado el actual gasto en personas mayores. 
ABío, G. et al. (2019): “Las cuentas nacionales de transferencias: aplicaciones y resultados para España”, Papeles de Economía Española, no 161 , págs. 114-137.

ATKINSON, A. (2011): "The case for universal child benefit", en WALKER, A.; SINFIELD, A. y WALKER, C. (eds.), Fighting Poverty, Inequality and Injustice. A Manifesto Inspired by Peter Townsend, Bristol, Policy Press, pp. 79-90.

AUTORIDAD INDEPENDIENTE DE RESPONSABILIDAD FISCAL (2020): Evolución del gasto público 2019. Estudio. Beneficios Fiscales, Autoridad Independiente de Responsabilidad Fiscal.

AVERETT, S. y WANG, Y. (2016): “Effects of higher EITC payments on children's health, quality of home environment, and noncognitive skills", Public Finance Review, vol. 46, nํㅜ 4 .

AVRAM, S. (2017): "Who benefits from the "hidden welfare state'? The distributional effects of personal income tax expenditure in six countries", Journal of European Social Policy, vol. 28, n- 3, pp. 271-293, 〈https://doi. org/10.1177/0958928717735061>.

AYALA, L. y CANTÓ, O. (2009): "Políticas económicas y pobreza infantil”, en VV. AA., Análisis y propuestas sobre pobreza infantil en España, Madrid, Unicef-Comité Español, pp. 10-40.

AYALA, L.; CANTÓ, O.; MARTÍNEZ LÓPEZ, R.; NAVARRO RUIZ, C. y ROMAGUERA DE LA CRUZ, M. (2020): Análisis de las necesidades sociales de la infancia, serie Informes, Observatorio Social La Caixa, <https://observatoriosociallacaixa.org/ es/informe-necesidades-sociales-infancia/>.

AZMAT, G. y GONZÁLEZ, L. (2010): “Targeting fertility and female participation through the income tax", Labour Economics, vol. 17, noㅡ
3, pp. 487-502, 〈https://doi.org/10.1016/j. labec0.2009.09.006).

BÁRCENA-MARTÍN, E.; BLANCO-ARANA, M.C. y PÉREZMORENO, S. (2015): "Assessing the impact of social transfer income packages on child poverty. A European cross-national perspective”, ECINEQ Working Papers, nํㅜ 410.

- (2018): "Social transfers and child poverty in European countries: Pro-poor targeting or pro-child targeting?", Journal of Social Policy, vol. 47, nํ- 4, pp. 739-758.

BASTIAN, J. y MICHELMORE, K. (2018): “The long-term impact of the earned income tax credit on children's education and employment outcomes", Journal of Labor Economics, vol. 36, no 4, pp. 1.127-1.163, 〈https://doi. org/10.1086/697477>.

BITLER, M.P. et al. (2018): “Cash for kids”, The Russell Sage Foundation Journal of the Social Sciences, vol. 4, n으 4, pp. 43-47.

BOCCUZZO, G., CALTABIANO, M.; ZUANNA, G.D. y LOGHI, M. (2008): "The impact of the bonus at birth on reproductive behaviour in a lowest-low fertility context: Friuli-Venezia Giulia (Italy), 1989-2005", Vienna Yearbook of Population Research, vol. 6, pp. 125-147.

BRADSHAW, J. (2011): "The case for family benefits", Children and Youth Services Review, vol. 34, no 3 , pp. 590-596.

BRADY, D. y BOSTIC, A. (2015): "Paradoxes of social policy: Welfare transfers, relative poverty, and redistribution preferences", American Sociological Review, vol. 80, nㅡㄹ, pp. 268-298, 〈https://doi.org/10.1177/0003122415573049〉.

BREWER, M.; RATCLIFFE, A. y SMITH, S. (2008): “Does welfare reform affect fertility? Evidence from 
UK”, Working Papers, no 08/09, The Institute for Fiscal Studies, <https://www.ifs.org.uk/ wps/wpo809.pdf〉.

CANTÓ, O. (2018): “El tamaño de las políticas públicas importa... y mucho", Agenda Pública, 30 de enero, 〈https://agendapublica.es/tamano-laspoliticas-publicas-importa-mucho/〉.

CANTÓ, O.; ADIEGO, M.; LEVY, H. y PANIAGUA, M. (2012): "Going regional. The effectiveness of different tax-benefit policies in combating child poverty in Spain", Euromod Working Papers, n 2/2012, <https://www.iser.essex.ac.uk/research/ publications/working-papers/euromod/em212.pdf>.

COMISIÓN EUROPEA (2013): “Recomendación de la Comisión, de 20 de febrero de 2013 , Invertir en la infancia: romper el ciclo de las desventajas", Diario Oficial de la Comisión Europea, 2-3-2013.

COOPER, K. y STEWART, K. (2017): “Does money affect children's ouctomes? An update”, CASEpapers, no 203 .

DAHL, G. y LOCHNER, L. (2009): “The impact of family income on child achievement: Evidence from the earned income tax credit", Discussions Papers, no 1.361-09, Institute for Research on Poverty, 〈https://www.irp.wisc.edu/ publications/dps/pdfs/dp136109.pdf〉.

DALY, M. y FERRAGINA, E. (2017): “Family policy in high-income countries: Five decades of development", Journal of European Social Policy, vol. 28, nํㅜ 3, pp. 255-270.

DOMÍNGUEZ-OLABIDE, P. (2021): “Prestaciones para la conciliación de la vida laboral y familiar: una revisión de su diseño e impacto en los países de la OCDE”, Zerbitzuan, nํㅜ 74, págs. \#\#-\#\#, 〈https://doi.org/10.5569/1134-7147.74.\#\#〉.

DRAGO, R.; SAWYER, K.; SHREFFLER, K.M.; WARREN, D. y WOODEN, M. (2011): “Did Australia's Baby Bonus increase fertility intentions and births?", Population Research and Policy Review, vol. 30, n으 3, pp. 381-397.

DUNCAN, G.J.; MORRIS, P.A. y RODRIGUES, C. (2011): “Does money really matter? Estimating impacts of family income on young children's achievement with data from random-assignment experiments", Developmental Psychology, vol. $47, \mathrm{n}^{\circ}-5$, pp. 1.263-1.279, <https://doi. org/10.1037/a0023875>.

ENGSTER, D. (2012): “Child poverty and family policies across eighteen wealthy Western democracies", Journal of Children and Poverty, vol. 18, $\mathrm{n} \div 2$, pp. 1-19, 〈https://doi.org/10.1080/10796126.2 012.710481〉.

ENGSTER, D. y STENSÖTA, H. (2011): “Do family policy regimes matter for children's well-being?”, Social Politics, vol. 18, nํㅜ 1, pp. 82-124, 〈https://doi.org/10.1093/sp/jxroo6〉.

EVANS, W.N. y GARTHWAITE, C.L. (2014): “Giving mom a break: The impact of higher EITC payments on maternal health", American Economic Journal: Economic Policy, vol. 6, nํ 2, pp. 258-290, 〈https://doi.org/10.1257/pol.6.2.258〉.

FERNÁNDEZ, G. (coord.) (2015): Hacia un sistema más inclusivo de garantía de rentas en España: diferentes alternativas de desarrollo, Madrid, Fundación Foessa.
FERRARINI, T; NELSON, K. y HÖÖG, H. (2012): “The fiscalization of child benefits in OECD countries", Gini Discussion Papers, nํ 49.

FORSTER, M. y VERBIST, G. (2014): “Prestaciones familiares, distribución de la renta y pobreza: el impacto de las transferencias para niños pequeños en 23 países europeos", Panorama Social, nํㅜ 20, pp. 105-119.

GAUTHIER, A.H. (2007): "The impact of family policies on fertility in industrialized countries: A review of the literature", Population Research and Policy Review, vol. 26, pp. 323-346.

GENNETIAN, L.; CASTELLS, N. y MORRIS, P. (2010): “Meeting the basic needs of children: Does income matter?", Children and Youth Services Review, vol. 32, no 9, pp. 1.138-1.148.

GONZÁLEZ, L. (2011): "The effects of a universal child benefit", Barcelona GSE Working Papers Series, no 574, 〈https://www.oecd.org/els/ emp/49115482.pdf〉.

- (2013): "The effects of a universal child benefit on conceptions, abortions and early maternal suply", American Economic Journal: Economic Policy, vol. 5, nํㅜ 3, pp. 160-188.

GONZÁLEZ, L. y TROMMLEROVA, S. (2020): “Cash transfers and fertility: How the introduction and cancellation of a child benefit affected births and abortions", Economics Working Paper Series, no 1.697, Universitat Pompeu Fabra.

GORNICK, J.C. y NELL, E. (2017): “Children, poverty, and public policy: A cross-national perspective”, LIS Working Paper Series, nํㅜ 701.

GREGG, P.; HURRELL, A. y WHITTAKER, M. (2012): Creditworthy. Assessing the Impact of Tax Credits in the Last Decade and Considering What This Means for Universal Credit, Londres, Resolution Foundation.

GUGUSHVILI, D. y LAENEN, T. (2019) “Twenty years after Korpi and Palme's paradox of redistribution: What have we learned so far, and where should we take it from here?", SPSW Working Papers, $\mathrm{n}$ 으, 〈https://lirias.kuleuven.be/2790635〉.

HAMAD, R. y REHKOPF, D.H. (2016): “Poverty and child development: A longitudinal study of the impact of the Earned Income Tax Credit", American Journal of Epidemiology, vol. 183 no 9, pp. 775-784 <https://doi.org/10.1093/aje/ kwv317〉.

HAMMER, B.; PRSKAWETZ, A.; GÁL, R.I.; VARGHA, L. y ISTENIČ T. (2019): “Human capital investment and the sustainability of public transfer systems across Europe: An evaluation based on national transfer accounts", Journal of Population Ageing, vol. 12, n 4, pp. 427-452, 〈https://doi.org/10.1007/s12062-018-9224-8〉.

HERNÁNDEZ ALEMÁN, A.; LEÓN, C.J. y MÁRQUEZ-RAMOS, L. (2017): "The effect of the Universal Child Care cash benefit on female labour supply in Spain", Estudios de Economía Aplicada, vol. 35, n으 3, 〈https://doi.org/10.25115/eea.v35i3.2508〉.

HOYNES, H.; MILLER, D. y SIMON, D. (2015): “Income, the Earned Income Tax Credit, and infant health", American Economic Journal: Economic Policy, vol. 7, nํㅜ 1, pp. 172-211, 〈https://doi. org/10.1257/pol.20120179'. 
HOYNES, H.; SIMON, D. y MILLER, D. (2012): "The EITC: Linking income to real health outcomes", Center for Poverty Research Policy Briefs, 〈https://poverty.ucdavis.edu/sites/main/files/ file-attachments/policy_brief_hoyes_eitc_o. pdf〉.

JACQUES, O. y NOËL, A. (2018): “The case for welfare state universalism, or the lasting relevance of the paradox of redistribution", Journal of European Social Policy, vol. 28, no 1, pp. 70-85, <https:// doi.org/10.1177/0958928717700564>.

JONES, L.E.; MILLIGAN, K.S. y STABILE, M. (2015): “Child cash benefits and familiy expenditures: Evidence form the National Child Benefit", NBER Working Paper Series, $\mathrm{n}$ - 21.101, 〈https:// doi.org/10.3386/w21101>.

KOEBEL, K. y SCHIRLE, T. (2015): “The differential impact of universal child benefits on the labor supply of married and single mothers", LCERPA Working Papers, no 2015-11, 〈http://www.lcerpa.org/ public/papers/LCERPA_2015_11.pdf〉.

KORPI, W. y PALME, J. (1998): “The paradox of redistribution and strategies of equality: Welfare state institutions, inequality, and poverty in the Western Countries", American Sociological Review, vol. 63, nํ5, pp. 661-687, 〈https://doi. org/10.2307/2657333>.

LAROQUE, G. y SALANIÉ, B. (2008): "Does fertility respond to financial incentives?", IZA Discussion Papers, n- 3.575, 〈http://ftp.iza.org/dp3575.pdf〉.

LUCl, A. y THEVENON, O. (2011): "The impact of family policy packages on fertility trends in developed countries”, Documents du Travail, no 174, París, Institut National d'Etudes Démographiques, <http://hdl.handle.net/20.500.12204/ $\mathrm{AW}_{2} \mathrm{NCdb}_{1} \mathrm{VV}_{5} \mathrm{GL} 3$ jekM>.

MAGDA, I.; KIEtCZEWSKA, A. y BRANDT, N. (2018): “The effects of large universal child benefits on female labour supply", IZA Discussion Papers, no 11652, 〈http://ftp.iza.org/dp11652.pdf〉.

MANOLI, D. y TURNER, N. (2018): “Cash-on-hand and college enrollment: Evidence from population tax data and the Earned Income Tax Credit", American Economic Journal: Economic Policy, vol. 10, n- 2, pp. 242-71, <https://doi.org/10.1257/ pol.20160298>.

MARÍ-KLOSE, P. (2019): La infancia que queremos. Una agenda para erradicar la pobreza infantil, Madrid, Los Libros de la Catarata.

MARÍ-KLOSE, M.; JULIÁ, A. y REDONDO, P. (2019): “El sistema de prestaciones y deducciones orientadas a la familia e infancia”, Documentos de Trabajo del VIII Informe sobre Exclusión y Desarrollo Social en España, nํㅜ 4.11, Madrid, Fundación Foessa.

MARX, I.; SALANAUSKAITE, L. y VERBIST, G. (2013): “The paradox of redistribution revisited: And that it may rest in peace?", IZA Discussion Papers, $\mathrm{n}$ 7.414, 〈http://ftp.iza.org/dp7414.pdf〉.

MATHIEU, S. (2013): “Entre l'effet tempo et l'effet quantum: une analyse de l'effet des politiques familiales sur la fécondité dans les pays avancés", Sociologie et Sociétés, vol. 45, noํ 1.

MAXFIELD, M. (2013): "The effects of the Earned Income Tax Credit on child achievement and longterm educational attainment”, Mich. State
Univ. Job Mark. Pap., <https://ippsr.msu.edu/ research/effects-earned-income-tax-creditchild-achievement-and-long-term-educationalattainment?.

MCKNIGHT, A. (2015): "A fresh look at an old question: Is pro-poor targeting of cash transfers more effective than universal systems at reducing inequality and poverty?", ImPRovE Working Papers, $\mathrm{n}^{\mathbf{0}}$ 15/14, 〈https://EconPapers.repec. org/RePEc:hdl:improv:1514〉.

MILLIGAN, K. (2002): "Subsidizing the stork: New evidence on tax incentives and fertility", NBER Working Paper Series, no 8.845, 〈https://www.nber.org/ papers/w8845.pdf〉.

MILLIGAN, K. y STABILE, M. (2011): "Do child tax benefits affect the wellbeing of children? Evidence from Canadian Child Benefit expansions", American Economic Journal: Economic Policy, vol. 3, 꾸 11.

MORISSENS, A. (2018): "The role of universal and targeted family benefits in reducing poverty in singleparent families in different employment situations", en NIEUWENHUIS, R. y MALDONADO, L.C., The Triple Bind of SingleParent Families, Bristol University Press; Policy Press, pp. 359-382.

MYCK, M. y TRZCIŃSKI, K. (2019): "From partial to full universality: The Family 500+ Programme in Poland and its labor supply implications", IFO DICE Reports, $\mathrm{n} \times 3$.

NICHOLS, A. y ROTHSTEIN, J. (2015): "The Earned Income Tax Credit (EITC)", NBER Working Paper Series, no 21211, 〈https://www.nber.org/papers/w21211. pdf〉.

NOGUERA, J.A. (2019): “Pobreza infantil y presupuestos: una auténtica prioridad”, Agenda Pública, 24 de enero, shttps://agendapublica.es/ pobreza-infantil-y-presupuestos-una-autenticaprioridad/>.

NOTTEN, G. y GASSMANN, F. (2008): “Size matters: Targeting efficiency and poverty reduction effects of means-tested and universal child benefits in Russia", Journal of European Social Policy, vol. 18, n- 3, pp. 260-274, 〈https://doi. org/10.1177/0958928708091059'.

OLIVER, X. y SPADARO, A. (2017): "Active welfare state policies and labour supply in Spain", Hacienda Pública Española, vol. 222, no 3, pp. 9-41.

PARR, N. y GUEST, R. (2011): “The contribution of increases in family benefits to Australia's early 21stcentury fertility increase: An empirical analysis", Demographic Research, vol. 25, pp. $215-244$, 〈https://doi.org/10.4054/ DemRes.2011.25.6〉.

PETIT, B. (2019): “Intergenerational effects of child-related tax benefits in the US", <https://borjapetit. github.io/files/papers/petit_childtax.pdf〉.

RAINER, H.; BAUERNSCHUSTER, S.; DANZER, N.; FICHTL, A.; HENER, T.; HOLZNER, C. y REINKOWSKI, J. (2014): "Child benefit and child allowances in Germany: Their impact on family policy goal", CESifo DICE Reports, n- 1/2014, <https://www. ifo.de/DocDL/dicereport114-rm1.pdf〉.

RIPHAHAN, R.T. y WIYNCK, F. (2017): "Fertility effects of child benefits”, IZA Discussion Papers, nํㅜ 10757, 〈http://ftp.iza.org/dp10757.pdf〉. 
SÁNCHEZ-BARRICARTE, J.J. (2017): “The long-term determinants of marital fertility in the developed world (19th and 2oth centuries): The role of welfare policies", Demographic Research, vol. 36, no-42, pp. 1.255-1.298.

SÁNCHEZ-MANGAS, R. y SÁNCHEZ-MARCOS, V. (2008): "Balancing family and work: The effect of cash benefits for working mothers", Labour Economics, vol. 15, n으, pp. 1.127-1.142.

SCHIRLE, T. (2015): "The effect of universal child benefits on labour supply", Canadian Journal of Economics, vol. 48, no 2 , pp. 437-463.

SINCLAIR, R.; BOYMAL, J. y DE SILVA, A. (2015): “A heterogeneous fertility response to a cash transfer policy: The Australian experience", [disponible en el SSRN] <https://doi. org/10.2139/ssrn.2722977>.

SKOCPOL, T. (1991): “Targeting within universalism: Politically viable policies to combat poverty in the United States", en JENCKS, C. y PETERSON, P.E. (eds.), The Urban Underclass, Washington D.C., The Brookings Institution, pp. 411-436.

SOLÉ, M.; SOUTO, G.; RENTERIA, E.; PAPADOMICHELAKIS, G. y PATXOT, C. (2020): "Protecting the elderly and children in times of crisis: An analysis based on National Transfer Accounts", The Journal of the Economics of Ageing, vol. 15, p. 100208, 〈https://doi.org/10.1016/j.jeoa.2019.100208〉.

STRELITZ, J. y LISTER, R. (2008): Why Money Matters: Family Income, Poverty and Children's Lives, Londres, Save The Children.

THÉVENON, O. y GAUTHIER, A.H. (2011): "Family policies in developed countries: A 'fertility-booster' with side-effects", Community, Work \& Family, vol. 14, no 2, pp. 197-216, 〈https://doi.org/10.1080/ 13668803.2011.571400〉.
THÉVENON, O. y LUCI, A. (2012): "Reconciling work, family and child outcomes: What Implications for family support policies?", Population Research and Policy Review, vol. 31, no 6, pp. 855-882, 〈https://doi.org/10.1007/s11113-012-9254-5〉.

THÉVENON, O.; MANFREDI, T.; GOVIND, Y. y KLAUZNER, I. (2018): "Child poverty in the OECD", OECD Social, Employment and Migration Working Papers, nำ 218, <https://doi.org/10.1787/ c69de229-en>.

VAN LANCKER, W. y VAN MECHELEN, N. (2015): “Universalism under siege? Exploring the association between targeting, child benefits and child poverty across 26 countries", Social Science Research, vol. 50, pp. 60-75.

VERBIST, G. y VAN LANCKER, W. (2016): "Horizontal and vertical equity objectives of child benefit systems: An empirical assessment for European countries", Social Indicators Research, vol. 128, nํ⒊

WALKER, A.; SINFIELD, A. y WALKER, C. (eds.) (2011): Fighting Poverty, Inequality and Injustice. A Manifesto Inspired by Peter Townsend, Bristol, Policy Press.

WHITEFORD, P. y ADEMA, W. (2007): "What works best in reducing child poverty", OECD Social, Employment and Migration Working Papers, $\mathrm{n}$ 51, 〈https://doi.org/10.1787/233310267230〉.

ZALAKAIN, J. (2019): “La fiscalización de las políticas sociales: funcionamiento e impacto de las deducciones fiscales reembolsables", Zerbitzuan, no 68, «https://doi. org/10.5569/1134-7147.68.08>. 